NASA/TM-2005-213196

\title{
Single-String Integration Test Measurements of the NEXT Ion Engine Plume
}

Aaron Snyder, Hani Kamhawi, and Michael Patterson

Glenn Research Center, Cleveland, Ohio

Melissa Britton

QSS Group, Inc., Cleveland, Ohio 
Since its founding, NASA has been dedicated to the advancement of aeronautics and space science. The NASA Scientific and Technical Information (STI) Program Office plays a key part in helping NASA maintain this important role.

The NASA STI Program Office is operated by Langley Research Center, the Lead Center for NASA's scientific and technical information. The NASA STI Program Office provides access to the NASA STI Database, the largest collection of aeronautical and space science STI in the world. The Program Office is also NASA's institutional mechanism for disseminating the results of its research and development activities. These results are published by NASA in the NASA STI Report Series, which includes the following report types:

- TECHNICAL PUBLICATION. Reports of completed research or a major significant phase of research that present the results of NASA programs and include extensive data or theoretical analysis. Includes compilations of significant scientific and technical data and information deemed to be of continuing reference value. NASA's counterpart of peerreviewed formal professional papers but has less stringent limitations on manuscript length and extent of graphic presentations.

- TECHNICAL MEMORANDUM. Scientific and technical findings that are preliminary or of specialized interest, e.g., quick release reports, working papers, and bibliographies that contain minimal annotation. Does not contain extensive analysis.

- CONTRACTOR REPORT. Scientific and technical findings by NASA-sponsored contractors and grantees.
- CONFERENCE PUBLICATION. Collected papers from scientific and technical conferences, symposia, seminars, or other meetings sponsored or cosponsored by NASA.

- SPECIAL PUBLICATION. Scientific, technical, or historical information from NASA programs, projects, and missions, often concerned with subjects having substantial public interest.

- TECHNICAL TRANSLATION. Englishlanguage translations of foreign scientific and technical material pertinent to NASA's mission.

Specialized services that complement the STI Program Office's diverse offerings include creating custom thesauri, building customized databases, organizing and publishing research results ... even providing videos.

For more information about the NASA STI Program Office, see the following:

- Access the NASA STI Program Home Page at http://www.sti.nasa.gov

- E-mail your question via the Internet to help@sti.nasa.gov

- Fax your question to the NASA Access Help Desk at 301-621-0134

- Telephone the NASA Access Help Desk at 301-621-0390

- Write to:

NASA Access Help Desk

NASA Center for AeroSpace Information 7121 Standard Drive

Hanover, MD 21076 
NASA/TM-2005-213196

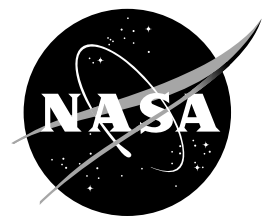

\section{Single-String Integration Test Measurements of the NEXT Ion Engine Plume}

Aaron Snyder, Hani Kamhawi, and Michael Patterson

Glenn Research Center, Cleveland, Ohio

Melissa Britton

QSS Group, Inc., Cleveland, Ohio

Prepared for the

40th Joint Propulsion Conference and Exhibit

sponsored by the AIAA, ASME, SAE, and ASEE

Fort Lauderdale, Florida, July 11-14, 2004

National Aeronautics and

Space Administration

Glenn Research Center 


\section{Acknowledgments}

Aaron Snyder thanks Brian Parma for his support in the area of data reduction software.

Available from

NASA Center for Aerospace Information 7121 Standard Drive

Hanover, MD 21076
National Technical Information Service 5285 Port Royal Road Springfield, VA 22100

Available electronically at http:/ /gltrs.grc.nasa.gov 


\title{
Single-String Integration Test Measurements of the NEXT Ion Engine Plume
}

\author{
Aaron Snyder, Hani Kamhawi, and Michael Patterson \\ National Aeronautics and Space Administration \\ Glenn Research Center \\ Cleveland, Ohio 44135 \\ Melissa Britton \\ QSS Group, Inc. \\ Cleveland, Ohio 44135
}

\begin{abstract}
Measurements were made of a $40 \mathrm{~cm}$ ion-thruster plume as part of the single-string-integration-test (SSIT) activity of Phase I of the NASA's Evolutionary Xenon Thruster (NEXT) project. The NEXT ion engine incorporates design improvements that extend NSTAR power levels and efficiencies. During SSIT, an engineering model (EM2) $40 \mathrm{~cm}$ engine was operated using an advanced xenon propellant system in combination with either a GRC power console or advanced power processing unit. Integral goals of the single-string phase were to characterize engine performance over the full input power range and to detail thruster operation within the specification of the NEXT throttle table. Plume diagnostics measurements of relative $\mathrm{Xe}^{+}$and $\mathrm{Xe}^{++}$currents were made using near-field and far-field ExB probes. Planar geometry faraday probes were used to obtain beam current density profiles. This paper reports on the characterization of the EM2 plume over a range of SSIT operating conditions, first with the advanced propellant management system teamed with the GRC power console and then with the power-processing unit.
\end{abstract}

\section{Introduction}

The need for advanced ion propulsion system capabilities has been demonstrated through in-space propulsion technology assessment analyses conducted by NASA. A higher power, higher throughput capability $25 \mathrm{~kW}$ ion propulsion system targeted for robotic exploration of the outer planets was identified as an enabling technology. This power level is an order of magnitude greater than that used on the Deep-Space 1 spacecraft $^{1}$ developed and

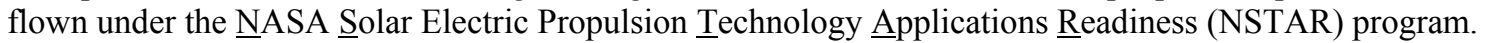

The NASA Headquarters Office of Space Science, Solar System Exploration Division, selected Glenn Research Center (GRC) to develop NASA's Evolutionary Xenon Thruster (NEXT) under the Next Generation Ion (NGI) Thruster Technology NASA Research Announcement. The NEXT team is composed of NASA GRC, the Jet Propulsion Laboratory (JPL), Aerojet Redmond Rocket Center, and Boeing Electron Dynamic Devices (BEDD), with significant participation by the Applied Physics Laboratory, University of Michigan (UM) and Colorado State University (CSU).

The Next Generation Electric Propulsion (NGEP) Project, managed by the NASA Marshall Space Flight Center, is a technology development project within the In-Space Propulsion Technology Program. The primary objective of NGI is to significantly increase performance for primary propulsion to planetary bodies by leveraging NASA's ion propulsion program for low thrust applications. The NEXT system is targeted for robotic exploration of the outer planets using $25 \mathrm{~kW}$-class solar-powered electric propulsion. The team will develop thruster, advanced power processing, xenon propellant management and gimbal technologies that will advance the ion propulsion state-of-art to meet the needs of such missions. ${ }^{2}$

Component performance was demonstrated over a one-year duration of NEXT phase I, which was completed in August 2003. These components included engineering model thrusters manufactured by NASA GRC, a breadboard power processor unit (PPU) manufactured by BEDD, and a breadboard propellant management system (PMS) developed by Aerojet. GRC manufactured, assembled, and conducted performance and life tests of EM thrusters in Phase I of the program. Details regarding the thruster design and performance have been published. ${ }^{3-6}$

Integration of the EPT with the Aerojet manufactured breadboard PMS and the BEDD manufactured breadboard PPU into a "single-string" configuration was one of the major activities of Phase I. The objectives of this SingleString Integration Test (SSIT) were multi-fold: demonstrate operation of the thruster within specification of the NEXT throttle table ${ }^{2}$ operating in concert with the breadboard PMS and PPU; verify full-functionality of the PMS and PPU; and, quantify other fault protection performance. The SSIT activities were conducted at NASA GRC, in 
the VF5 chamber. A description of the SSIT system configuration, with particular delineation of three subsystems (the thruster, PPU, and PMS), has recently been discussed in a related paper, which details the performance of the subsystems and of the system. The SSIT was executed with elements incorporated in a sequential fashion. After completion of initial performance tests of the EM2 thruster on laboratory elements, the Aerojet PMS was connected to the thruster to deliver the xenon propellant, while power was delivered via a laboratory power console (PC). Subsequent to thruster/PMS integration tests with the PC, the PPU was electrically connected to the thruster forming a complete single-string configuration of thruster/PMS/PPU.

This paper presents the two sets of SSIT plume diagnostic measurements obtained to supplying EM2 thruster power using the PC and the PPU. Characterization of the exhaust plume of an ion thruster is vital to evaluating thruster performance, predicting lifetimes of various thruster components, and discerning the impact of thruster operation upon sensitive spacecraft components. Knowledge of the dependence of charged species fraction in the exhaust beam upon primary thruster parameters over a wide range of operation is essential in order to adequately address each of these essential areas. In the SSIT, two standard diagnostic probe techniques were used to provide key data concerning the thruster plume. As one of the diagnostic techniques, a pair of $\mathbf{E x B}$ probes were used to sample the ion currents $\mathrm{J}^{+}$and $\mathrm{J}^{++}$corresponding to the number of singly charged xenon ions $\mathrm{Xe}^{+}$, and the number of doubly charged xenon ions $\mathrm{Xe}^{++}$collected, respectively. The double-to-single ion current ratio $\mathrm{J}^{++} / \mathrm{J}^{+}$of the exhaust plume affects thruster performance and impacts service lifetime. Specific performance data influenced by the current ratio include thrust magnitude and thrust vectoring. Lifetime issues include screen grid wear, which correlates with an abundance of $\mathrm{Xe}^{++}$. Although the impact of species fraction upon general spacecraft components is very design specific, a detailed knowledge of exhaust beam composition would be invaluable toward overall spacecraft design. The second plume diagnostic technique employed in the SSIT consisted of a set of faraday probes measuring radial beam density profiles. Using faraday probes to obtain beam profiles is both a practical and standard method to determine the radial variation in both beam current density and beam divergence. Knowledge of these two factors is important in calculating thruster performance and predicting component lifetime. From the radial variation in beam current densities, the degree of beam flatness (which is a measure of the average beam current density relative to the peak beam current density) can be calculated. Improved beam flatness is expected to extend accelerator grid service life. As just outlined, these two above mentioned diagnostic tools provide valuable information of the exhaust plume.

This paper reports on the characterization of the EM2 plume over a range of SSIT operating conditions. Whereas the faraday probes were used occasionally, the pair of $\mathbf{E x B}$ probes was used extensively during the SSIT to provide data on the EM2 thruster plume. The primary objective of this paper is to document the ion current ratios $\mathrm{J}^{++} / \mathrm{J}^{+}$and some of the beam current density profiles that were obtained during the SSIT. For particular purposes the dependence of $\mathrm{J}^{++} / \mathrm{J}^{+}$and beam current density upon specific thruster parameters such as beam voltage, input power, and discharge propellant utilization efficiency is presented and discussed. In addition some comparisons are made between SSIT and previous NEXT phase I results and between SSIT and selected NSTAR results.

\section{SSIT Test Hardware}

Single-String integration testing was executed at NASA GRC's Vacuum Facility $5 .^{7}$ For the SSIT the configuration was as follows: The thruster (EPT EM2) was mounted within the vacuum facility along its centerline, contiguous with a motion control system configured with near-field diagnostics (Faraday and $\mathbf{E} x \mathbf{B}$ plasma probes) to measure ion plume characteristics; in addition, a far-field $\mathbf{E} x \mathbf{B}$ probe was mounted on axis from the facility's center mast. The PMS High Pressure Assembly was simulated with laboratory equipment located external to the vacuum facility, with the Low Pressure Assembly plumbed internal to the facility in close-coupled proximity to the thruster. Both the PC and the BB PPU were located external to the vacuum facility, with high voltage cabling routed through vacuum penetrations to the thruster. Figure 1 shows the thruster and PMS elements internal to the vacuum facility.

This section presents descriptions of the test apparatus including the three subsystems in the SSIT (thruster, PPU, PMS), vacuum facility, and beam diagnostics.

\section{A. SSIT Thruster (EM2)}

The SSIT EM2 (reference fig. 1) is one of three EM $40 \mathrm{~cm}$ diameter thrusters designed and manufactured at NASA GRC for the NEXT project. The engine performance requirements include a specific impulse of at least $4050 \mathrm{~s}$ at full power, and thruster efficiencies of greater than 0.67 at full power and greater than 0.42 at low power. Thruster lifetime goals require a $405 \mathrm{~kg}$ lifetime propellant throughput capability, which corresponds to 1.5 times the propellant throughput requirement $(270 \mathrm{~kg})$ at maximum power. To achieve these performance levels with the 
EM thruster, significant advancements in ion-engine technology over the NSTAR ion engine were made. These improvements include: a magnetic circuit design that enhanced beam flatness and reduced discharge losses; hightemperature stabilized rare-Earth magnets; a compact propellant isolator; and advanced ion optics and discharge cathode designs that extended operational life.

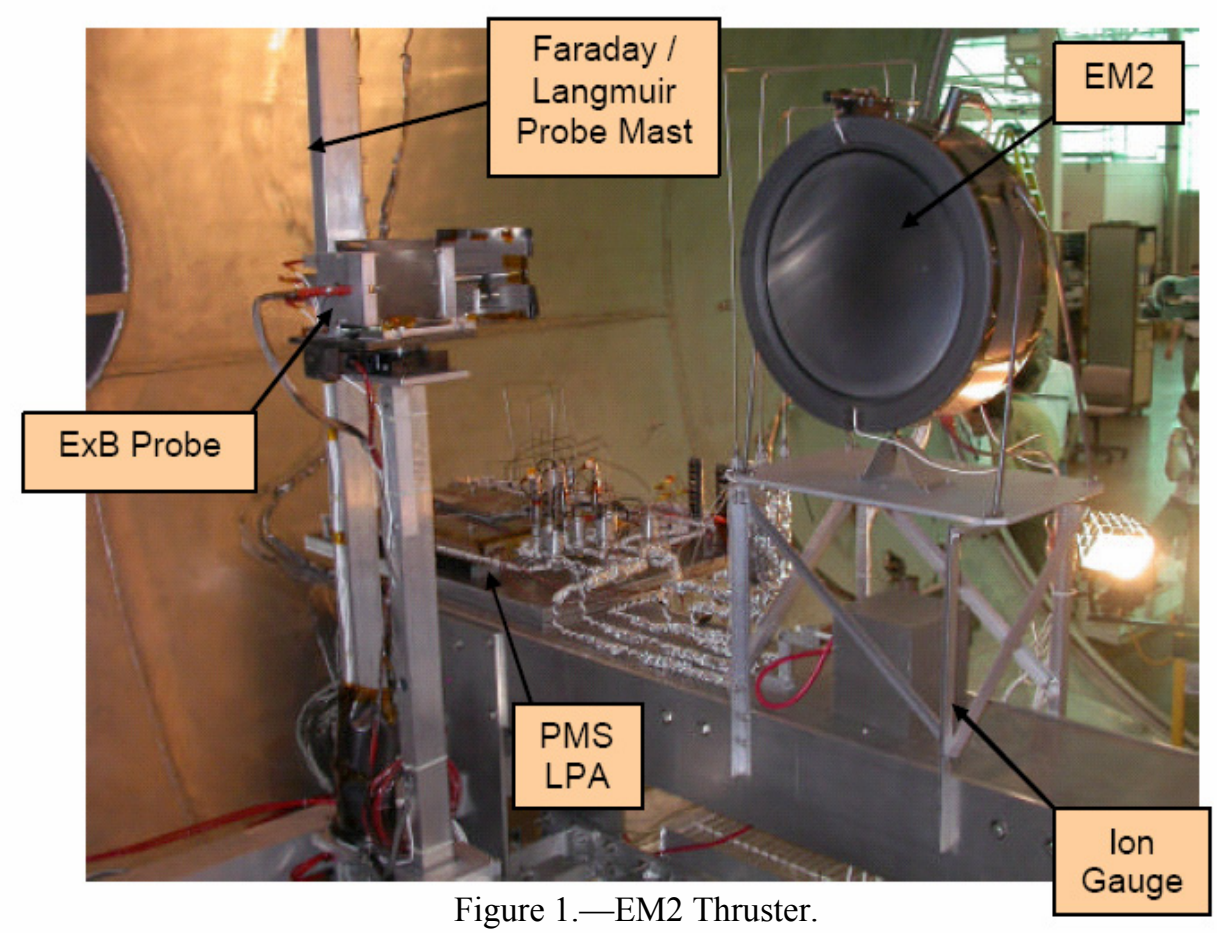

\section{B. Breadboard Power Processor Unit (PPU)}

The breadboard PPU for the NEXT project was designed and built by BEDD under contract with NASA GRC. It contains six power supplies that are required to operate the ion thruster and a housekeeping power supply for internal PPU functions (see fig. 2). The most important power supply is the high-voltage beam supply, which produces and processes up to 92 percent of the power in the system. The beam supply consists of six individual $1.1 \mathrm{~kW}$ modules that operate in parallel. The modules use a dual-bridge phase-modulated/pulse-width-modulated topology for low switching losses and performance over a wide input/output voltage range. Except for some increases in output capacity and a higher switching frequency of $50 \mathrm{kHz}$ to reduce mass, the other power supplies in the PPU use the same topologies as the NSTAR PPU. Better MOSFETs and new gate drive circuits were used to improve efficiency and to simplify the design., ${ }^{8,9}$

\section{Breadboard Propellant Management System (PMS)}

The Propellant Management System (PMS) for NASA's Evolutionary Xenon Thruster (NEXT) delivers low pressure gas to the thruster and two cathodes from a supercritical xenon supply source. Independent, accurate throttling of propellant mass flow rate is required for each flow branch (Main Discharge Chamber, Discharge Cathode and Neutralizer Cathode). Propellant mass flow rate is controlled to each branch using calibrated thermal throttles, which are fed by a common pressurized manifold using a Proportional Flow Control Valve (PFCV) developed by Moog Inc. ${ }^{10}$ A thermal throttle is comprised of a porous metal flow restrictor that is temperature controlled through the use of a platinum temperature sensor and resistive heater. 


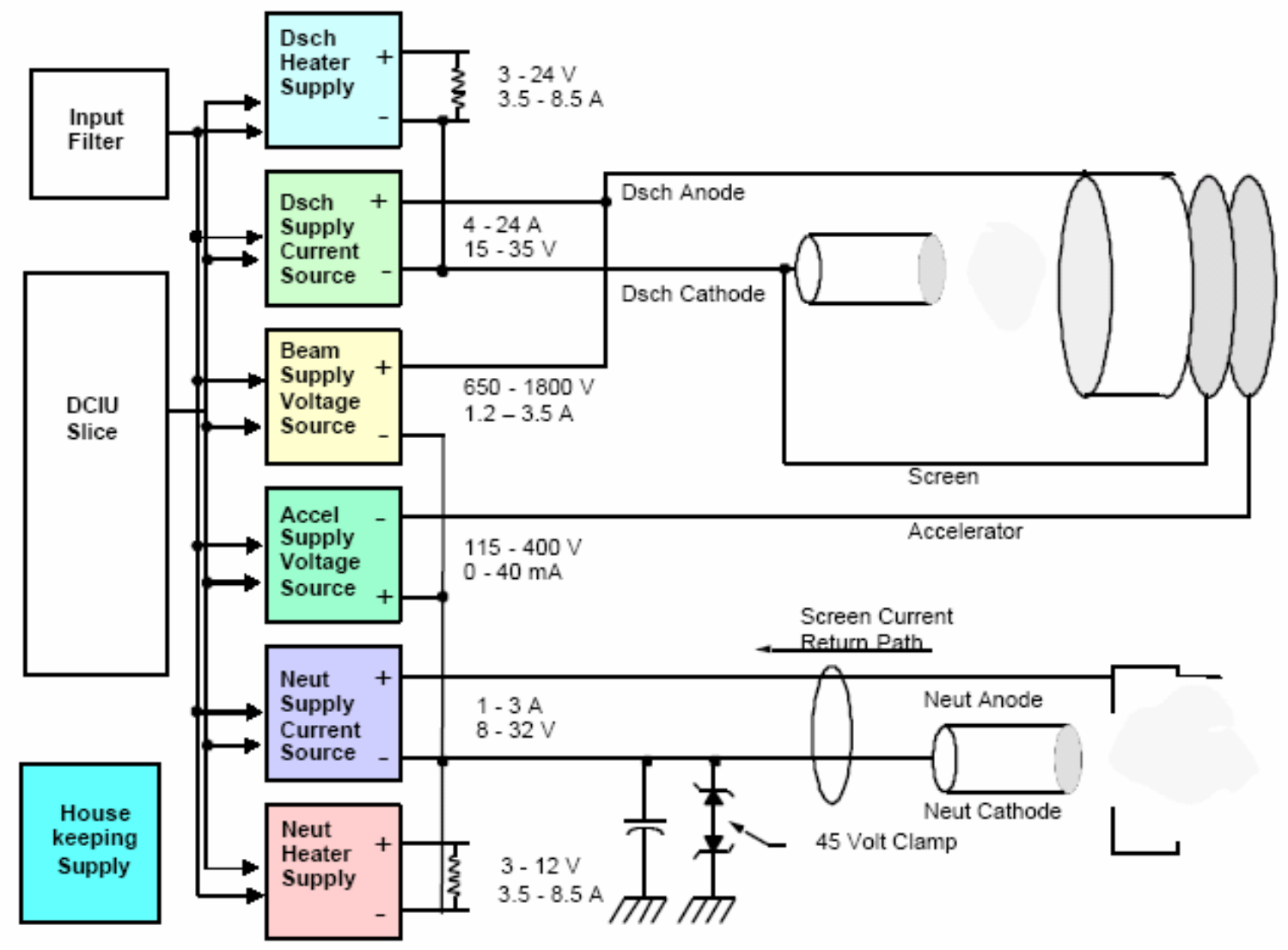

Figure 2.-Breadboard PPU for NEXT.

\section{Vacuum Facility}

NASA GRC's Vacuum Facility 5 is a $4.6 \mathrm{~m}$ diameter by $19.2 \mathrm{~m}$ long space simulation chamber with a pumping speed in excess of $1.5 \times 10^{6} \mathrm{l} / \mathrm{s}$ (xenon). It is evacuated using two pumping systems. Half the vacuum chamber houses helium cryopanels, which are isolated from direct impingement of the thruster exhaust plume by a mid-tank shield. The cryopanels have a $27 \mathrm{~m}^{2}$ surface area operated at $4.7 \mathrm{~K}$ with liquid helium and 4.7 to $20 \mathrm{~K}$ with gaseous helium. The bottom of the vacuum chamber houses twenty $81.3 \mathrm{~cm}$ diameter $(30,000 \mathrm{l} / \mathrm{s})$ oil-diffusion pumps charged with D.C. 705 oil. The diffusion pumps are backed by four $(85,700 \mathrm{l} / \mathrm{s})$ rotary-lobe blowers that exhaust into four $(15,150 \mathrm{l} / \mathrm{s})$ rotary-piston pumps. Above the diffusion pumps are single bounce, optically dense, chevron-type traps cooled to $-32{ }^{\circ} \mathrm{C}$. The chamber can reach an ultimate vacuum level of $1.1 \times 10^{-4} \mathrm{~Pa}\left(8 \times 10^{-7}\right.$ torr $)$. Facility background pressures during SSIT testing ranged between $3.6 \times 10^{-4} \mathrm{~Pa}\left(2.7 \times 10^{-6}\right.$ torr $)$ to $1.14 \times 10^{-3} \mathrm{~Pa}\left(8.6 \times 10^{-6}\right.$ torr $)$.

\section{E. Beam Diagnostics}

The diagnostic devices to measure thruster plume properties consisted of a set of faraday probes and two $\mathbf{E} x \mathbf{B}$ probes. In the following discussion, the faraday probe results are presented first and then the $\mathbf{E} x \mathbf{B}$ probe results are presented.

Circular planar faraday probes were employed to perform ion beam diagnostics. The probes had a $1 \mathrm{~cm}^{2}$ circular current-collecting area made from molybdenum. Three probes were mounted on the probe rake which was in turn mounted onto a two-axis probe motion system for measuring the ion beam current densities and plasma properties. The middle probe, designated probe 2, was aligned with the engine center. Probes 1 and 3 were situated $3.8 \mathrm{~cm}$ above and below probe 2 , respectively. The positioning system swept the probes in the radial (X) and axial (Y) directions downstream of the engine ion optics, with $1.5 \mathrm{~m}$ travel in each axis. The X-Y motion system was positioned to intercept the ion beam primarily beyond the $30^{\circ}$ half-angle. The probes' wiring was routed within the probe rake tubing to the base of the rake post. To measure the ion beam current density profiles, the probes were biased 30 volts negative with respect to the beam plasma potential to repel electrons and were connected through 
separate resistors that act as shunts to measure collected currents. Probe sweeps were conducted at 45, 120, 195, 270 , and $345 \mathrm{~mm}$ from the thruster face.

Two $\mathbf{E} x \mathbf{B}$ probes, differing in design detail, were used to measure relative double and single ion current densities. The first $\mathbf{E} x \mathbf{B}$ probe, used for near-field measurements and constructed at JPL, was mounted next to the faraday-probe array on the dual-axis positioning system at an elevation equal to that of the thruster's axis. The second $\mathbf{E} x \mathbf{B}$ probe, constructed by ZIN Technology and used for far-field measurements, was mounted in a fixed position along the thruster axis and supported by the chamber's mid-channel mast. Figure 3 presents a schematic of the $\mathbf{E} x \mathbf{B}$ probes and illustrates the three main probe components. The $\mathbf{E} x \mathbf{B}$ devices consist of: (1) a collimating section with circular apertures at each end that define the ion sample region at the thruster's optics; (2) a field region consisting of crossed electric and magnetic fields used to sort ions by velocity; and (3) an exit slit collimator that permits ions of resolved velocity to pass through and arrive at the collector surface. Table I lists key attributes of the two ExB probes. In particular regarding the object diameter attribute, inspection of the table indicates that as compared to the far-field probe $(18 \mathrm{~cm})$, the near-field probe $(1.1 \mathrm{~cm})$ sampled ions emerging from a much more localized region of the accelerator grid.

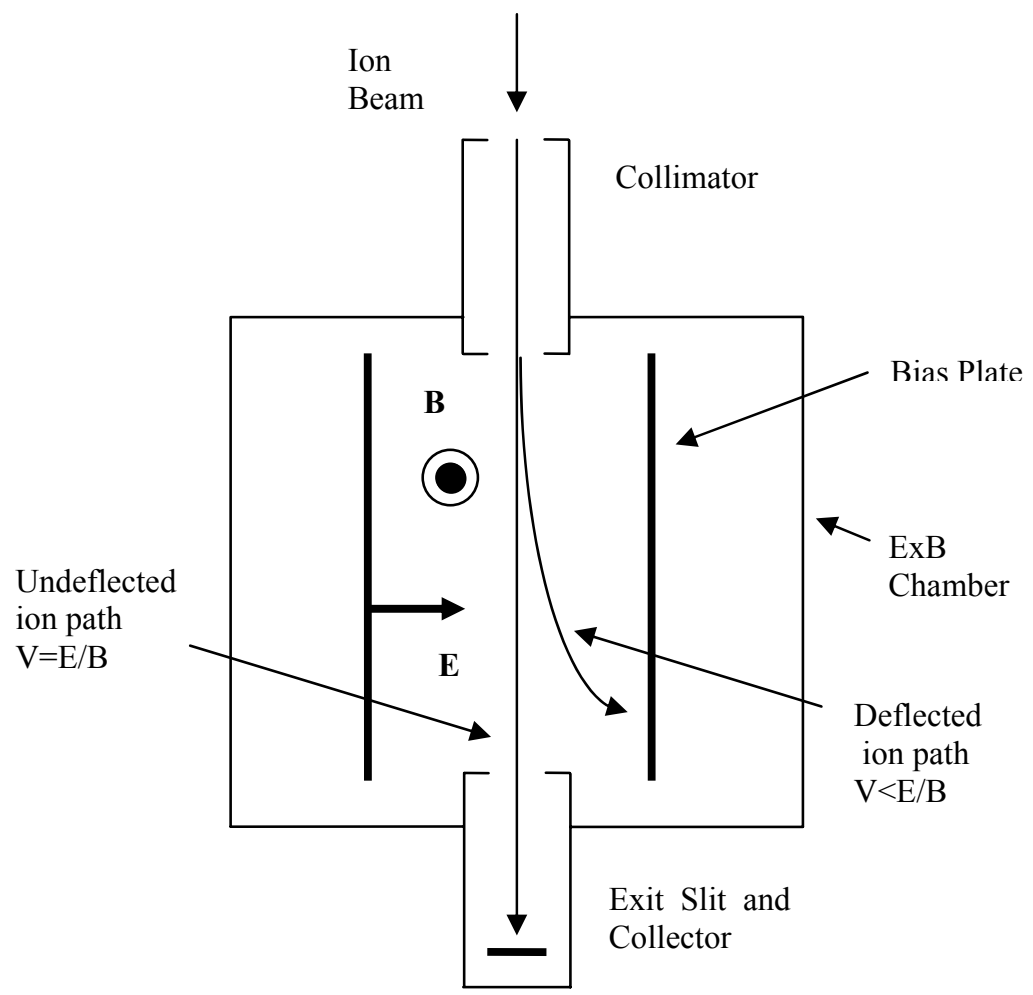

Figure 3.-ExB Probe Schematic.

Table I.-Attributes of ExB probes.

\begin{tabular}{lll}
\hline ExB probe attribute & Near Field & Far Field \\
\hline Collimator length, cm & 15.2 & 7.6 \\
ExB field length, cm & 12.7 & 15.2 \\
Exit-slit-to-collector length, cm & 1 & 1.5 \\
Bias potential for $1800 \mathrm{~V} \mathrm{Xe}, \mathrm{V}$ & 200 & 65 \\
$\mathrm{~B}, \mathrm{~T}$ & 0.13 & 0.09 \\
Bias plate separation, cm & 2.8 & 1.4 \\
Entrance aperture, cm & 0.05 & 0.16 \\
Collimating aperture, cm & 0.05 & 0.16 \\
Exit slit width, cm & 0.20 & 0.32 \\
Object diameter on grid, cm & 1.1 & 18 \\
Probe-to-thruster distance, cm & 152 & 417 \\
Ion collector & Aluminum faraday cup & Tungsten-coated disk \\
\hline
\end{tabular}


In the following, $\mathrm{J}^{+}$and $\mathrm{J}^{++}$denote the electrical currents corresponding to the collected $\mathrm{Xe}^{+}$and $\mathrm{Xe}^{++}$ions, respectively. The currents $\mathrm{J}^{++}$and $\mathrm{J}^{+}$were measured using a commercially available programmable electrometer and the bias plate voltage was supplied using a commercially available high-voltage source measure unit. The source allowed application of a constant voltage or a ramped voltage to the bias plates. When using the ramp mode, the voltage was increased in a stepwise fashion from an initial value to a final value at a rate of $0.5 \mathrm{~V} / \mathrm{s}$ with a $0.5 \mathrm{~s}$ delay between steps. For a given plate voltage ions lying within a velocity band are collected, irrespective of their charge. However, since ions of similar mass accelerated by a common potential achieve velocities proportional to the square root of their charge, the bias potential required to measure $\mathrm{Xe}^{++}$ions is greater than that applied to measure $\mathrm{Xe}^{+}$ions. For an ion thruster, the bands for the two species typically appear as separated peaks. The measured ion currents $\mathrm{J}^{+}$and $\mathrm{J}^{++}$were recorded as functions of applied bias plate voltage using a commercially available oscilloscope. The specific voltage range to measure the peaks varies and depends on the beam voltage, $\mathrm{V}_{\mathrm{b}}$, and on the particular $\mathbf{E} x \mathbf{B}$ probe. The exit-slit widths of the $\mathbf{E} x \mathbf{B}$ probes were chosen to assure that the peaks corresponding to the single and double ion signals did not overlap. In the normal mode of operation the bias plates were ramped through a voltage range sufficient to capture both the single and the double ion peaks. Normal mode measurements were made with the probes at a fixed position. In addition, a "sweep" mode of operation was used in which the near-field probe, biased to a constant voltage corresponding to the peak of a $\mathrm{Xe}^{+}$ion or $\mathrm{Xe}^{++}$ion as determined by a prior run using the normal mode of operation, performed a sweep across the beam to record a "peak" beam profile. To obtain $\mathrm{J}^{+}$and $\mathrm{J}^{++}$using the sweep method, the near-field probe was swept twice through the exhaust plume, once using the plate bias voltage corresponding to the $\mathrm{Xe}^{+}$peak and, again, using the voltage corresponding to the $\mathrm{Xe}^{++}$peak.

When not operational, all movable probes were positioned outside the plume to minimize backsputtering onto the engine. Also to reduce backsputtering, each $\mathbf{E} x \mathbf{B}$ probe had a low-sputter shield installed between it and the thruster. Each shield had a small shuttered orifice $(6 \mathrm{~mm}$ diameter) which was actuated for ion passage.

\section{Results and Discussion}

After completion of initial performance tests of the EM2 thruster on laboratory elements, the Aerojet PMS was connected to the thruster to deliver the xenon propellant, while power was delivered via a laboratory power console. During this portion of the test, the thruster was operated over the full power throttling range. Thruster performance was calculated from electrical measurements obtained from digital multimeters on the output of the power supplies. Data obtained included ion optics (perveance and electron backstreaming), neutralizer, plume, and thruster temperature measurements, along with characterization of overall thruster performance.

The following sections present and discuss SSIT diagnostic measurements for the thruster's plume. When operating the thruster using the PC and PMS, near-field radial beam current profiles and both near-field and far-field double-to-single ion current ratios were obtained. Only far-field double-to-single ion current ratios were obtained when the thruster was operated with both the PPU and the PMS. The beam current profiles results are compared to the performance test results.

\section{A. Near-field Radial Beam Current Density Profiles}

For the purpose of establishing a reference basis and for comparison of NEXT SSIT operation to other NEXT engine data, radial beam profiles were obtained during EM2 operation when the PC was used to supply the thruster power. Regarding beam current density measurements, no attempt was made to repel charge exchange ions from the probe or to account for secondary electron emission due to ion bombardment. Figure 4 presents radial ion beam current density profiles for thruster beam current of $1.2 \mathrm{~A}$ at a beam power supply voltage of $1021 \mathrm{~V}$, whereas, figure 5 presents radial ion beam current density profiles at a thruster beam current of $3.52 \mathrm{~A}$ at beam power supply voltage of $1800 \mathrm{~V}$. For both figures the ion beam current density profiles were acquired at 45, 120, 195, 270, and $345 \mathrm{~mm}$ downstream from the ion optics surface. Results in fig. 4 and fig. 5 indicate that $45 \mathrm{~mm}$ downstream from the ion optics, peak current density at the thruster ion beam current of $1.2 \mathrm{~A}$ was $1.53 \mathrm{~mA} / \mathrm{cm}^{2}$ which is within 1 percent of the peak current density of $1.54 \mathrm{~mA} / \mathrm{cm}^{2}$ which was measured during the $2000 \mathrm{~h}$ wear test. ${ }^{11}$ Also, results in fig. 5 indicate that $45 \mathrm{~mm}$ downstream from the ion optics, peak current density at the thruster ion beam current of $3.52 \mathrm{~A}$ was $3.97 \mathrm{~mA} / \mathrm{cm}^{2}$ which matches the value measured during the $2000 \mathrm{~h}$ wear test ${ }^{11}$ As both figures demonstrate, the shape functions of the ion current density profiles were similar at all beam currents evaluated. Integration of the radial beam current density profiles (assuming azimuthal symmetry) yielded beam currents that were higher than the measured beam current by as much as 15 percent. Possible sources of error are discussed in the literature. ${ }^{12,13}$ 


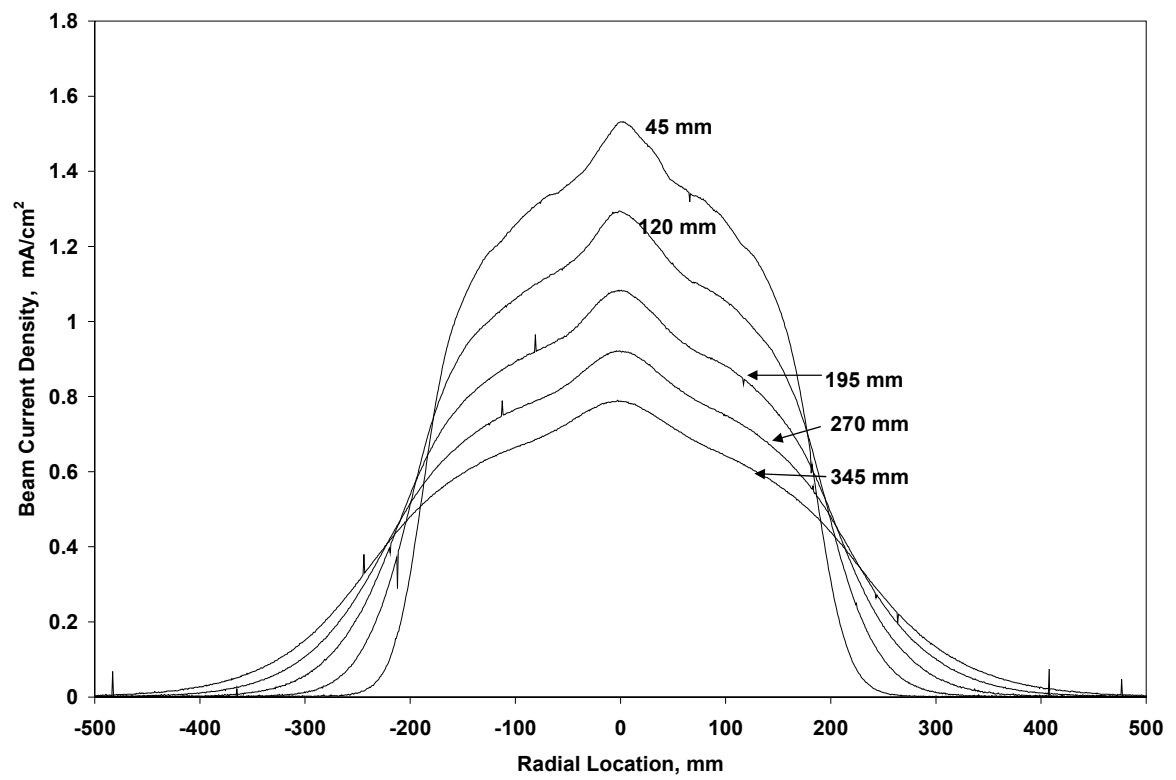

Figure 4.--Radial current density profiles at 45, 120, 195, 270, and $345 \mathrm{~mm}$ from thruster face for thruster beam current of $1.2 \mathrm{~A}$ and beam power supply voltage of $1021 \mathrm{~V}$.

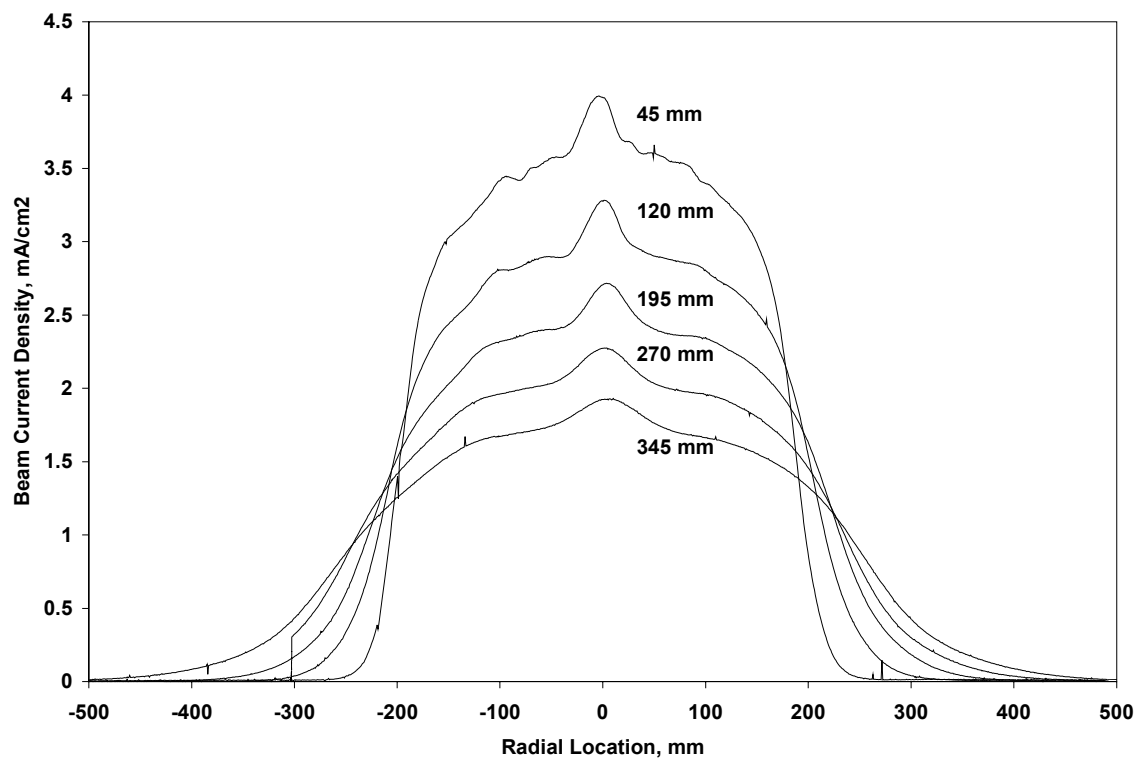

Figure 5.-Radial current density profiles at 45, 120, 195, 270, and $345 \mathrm{~mm}$ from thruster face for thruster beam current of $3.52 \mathrm{~A}$ and beam power supply voltage of $1800 \mathrm{~V}$.

The beam flatness parameter, defined as the ratio of average-to-peak ion current density, is a key lifetime indicator. Flatness parameters of 0.59 and 0.70 were calculated for the $1.2 \mathrm{~A}$ and $3.52 \mathrm{~A}$ EM2 thruster operation. For the $1.2 \mathrm{~A}$ case, the flatness parameter value is within 3 percent of the 0.61 value calculated during the $2000 \mathrm{~h}$ wear test (using EM1). ${ }^{11}$ For the $3.52 \mathrm{~A}$ thruster operation, a flatness parameter of 0.70 was calculated and is within 1.4 percent of the value calculated during the $2000 \mathrm{~h}$ wear test (using EM1). ${ }^{11}$ Comparing the NEXT and NSTAR flatness parameters indicated that the NEXT EM1 ion engine beam flatness parameters were 45 to 85 percent higher than those of the NSTAR ion engine. ${ }^{5,12}$ Higher flatness parameters apparently correspond directly with increased electron backstreaming limits, and are speculated to have contributed to increases in ion optics perveance and screen grid ion transparencies relative to those of the $30 \mathrm{~cm}$ ion optics on an NSTAR engine. The higher beam flatness parameters of the NEXT ion engine can also lead to reduced accelerator aperture enlargement near the grid center. 
This is because charge-exchange production is directly proportional to the number density of beam ions, which has been significantly reduced near the grid center of this engine. Because accelerator grid aperture enlargement is a primary grid failure mechanism, the higher beam flatness parameters of the NEXT ion engine should enhance accelerator grid service life. The present SSIT results support that NEXT ion engines produce higher beam flatness parameters leading to reduced accelerator aperture enlargement near the grid center, and, therefore, increased accelerator grid service life.

\section{B. Double-to-Single Ion Current Ratio $\mathbf{J}^{++} / \mathbf{J}^{+}$}

Two sets of results for the double-to-single ion-current ratio $\mathrm{J}^{++} / \mathrm{J}^{+}$are presented. The first set was obtained with the EM2 thruster powered by the PC and the second set was obtained with the EM2 thruster powered by the PPU corresponding to when the SSIT activity was fully integrated. Table II shows the portion of the NEXT throttle table that involved $\mathbf{E} x \mathbf{B}$ measurements.

Table II.-Portion of NEXT throttle table spanning SSIT ExB results.

\begin{tabular}{|c|c|c|c|c|}
\hline $\mathrm{P}_{\mathrm{in}}, \mathrm{W}$ & Specific Impulse, $\mathrm{s}$ & Eff & Thrust & Beam Current \\
\hline \multicolumn{5}{|c|}{$1800 \mathrm{~V} \mathrm{~V}_{\mathrm{pbs}},-250 \mathrm{~V} \mathrm{~V}_{\mathrm{a}}$} \\
\hline 6850 & 4120 & 0.698 & 237 & 3.52 \\
\hline 6055 & 4090 & 0.691 & 209 & 3.10 \\
\hline 3960 & 3950 & 0.658 & 135 & 2.00 \\
\hline 2425 & 3600 & 0.589 & 80.8 & 1.20 \\
\hline \multicolumn{5}{|c|}{$1567 \mathrm{~V} \mathrm{~V}_{\mathrm{pbs}},-235 \mathrm{~V} \mathrm{~V}_{\mathrm{a}}$} \\
\hline 6030 & 3840 & 0.691 & 221 & 3.52 \\
\hline 2140 & 3360 & 0.58 & 75.4 & 1.20 \\
\hline \multicolumn{5}{|c|}{$1396 \mathrm{~V} \mathrm{~V}_{\mathrm{pbs}},-220 \mathrm{~V} \mathrm{~V}_{\mathrm{a}}$} \\
\hline 5425 & 3625 & 0.683 & 209 & 3.52 \\
\hline 1940 & 3170 & 0.571 & 71.1 & 1.20 \\
\hline \multicolumn{5}{|c|}{$1179 \mathrm{~V} \mathrm{~V}_{\mathrm{pbs}},-200 \mathrm{~V} \mathrm{~V}_{\mathrm{a}}$} \\
\hline 4660 & 3330 & 0.671 & 192 & 3.52 \\
\hline 4125 & 3300 & 0.663 & 169 & 3.10 \\
\hline 3610 & 3270 & 0.653 & 147 & 2.70 \\
\hline 2715 & 3190 & 0.627 & 109 & 2.00 \\
\hline 1675 & 2910 & 0.557 & 65.3 & 1.20 \\
\hline \multicolumn{5}{|c|}{$1021 \mathrm{~V} \mathrm{~V}_{\mathrm{pbs}},-175 \mathrm{~V} \mathrm{~V}_{\mathrm{a}}$} \\
\hline 1485 & 2710 & 0.543 & 60.7 & 1.20 \\
\hline \multicolumn{5}{|c|}{$850 \mathrm{~V} \mathrm{~V}_{\mathrm{pbs}},-125 \mathrm{~V} \mathrm{~V}_{\mathrm{a}}$} \\
\hline 1280 & 2465 & 0.522 & 55.3 & 1.20 \\
\hline \multicolumn{5}{|c|}{$679 \mathrm{~V} \mathrm{~V}_{\mathrm{pbs}},-115 \mathrm{~V} \mathrm{~V}_{\mathrm{a}}$} \\
\hline 1075 & 2200 & 0.495 & 49.3 & 1.2 \\
\hline
\end{tabular}

\section{1. $J^{++} / J^{+}$with PC and PMS}

The first set of ExB probe measurements were obtained on the EM2 thruster plume with the Aerojet PMS connected to the thruster to deliver the xenon propellant, while power was delivered via laboratory power console. During this portion of the test, the thruster was operated over the full-power throttling range. Over a portion of this range, both far-field and near-field $\mathbf{E} x \mathbf{B}$ measurements were obtained, with most of the data obtained using the farfield probe. A synopsis of the data is presented in table III with the data arranged chronologically and grouped by differing run dates; the near-field data is denoted according operation mode, i.e., according to normal stationary mode or sweep mode.

As a specific example of the first set of $\mathbf{E} x \mathbf{B}$ plume data, the operating case for $\mathrm{V}_{\mathrm{b}}=1800 \mathrm{~V}, \mathrm{~J}_{\mathrm{b}}=3.52 \mathrm{~A}$ $\left(\mathrm{P}_{\text {in }}=6870 \mathrm{~W}\right.$ in table III) is discussed in detail. For this case, both the far-field and near-field probes were used with the near-field probe operated in both the stationary and sweep modes. In the course of obtaining ExB plume data, the assumed on-axis beam position for the near-field probe was adjusted laterally by $+13 \mathrm{~mm}$. This is reflected in table III where $\mathrm{x}=0$ corresponds to the corrected position. 
Table III.-SSIT EPT EM2 using PC and PMS.

\begin{tabular}{|c|c|c|c|c|c|c|c|c|c|c|c|}
\hline Point & $\begin{array}{c}\mathrm{V}_{\mathrm{bps}} \\
\mathrm{V} \\
\end{array}$ & $\begin{array}{c}\mathrm{J}_{\mathrm{bps}} \\
\mathrm{A} \\
\end{array}$ & $\begin{array}{l}\mathrm{P}_{\text {in }} \\
\mathrm{W}\end{array}$ & $\begin{array}{l}\mathrm{I}_{\mathrm{s}} \\
\mathrm{S}\end{array}$ & Thrust Eff. & $\begin{array}{c}\text { Thrust } \\
\mathrm{mN}\end{array}$ & $\begin{array}{l}\text { Dis. Prop. } \\
\text { Eff. }\end{array}$ & $\mathrm{J}^{++} / \mathrm{J}^{+}$ & Probe & $\begin{array}{c}\mathrm{x} \\
\mathrm{mm} \\
\end{array}$ & $\begin{array}{r}\mathrm{y} \\
\mathrm{mm} \\
\end{array}$ \\
\hline 1 & 1179 & 2.008 & 2710 & 3180 & 0.628 & 109 & 0.891 & 0.066 & Far & 0 & 4170 \\
\hline 2 & 1179 & 2.008 & 2710 & 3180 & 0.628 & 109 & 0.891 & 0.065 & Far & 0 & 4170 \\
\hline 3 & 1800 & 2.003 & 3950 & 3940 & 0.661 & 135 & 0.892 & 0.055 & Far & 0 & 4170 \\
\hline 4 & 679 & 1.207 & 1080 & 2210 & 0.500 & 49.7 & 0.861 & 0.043 & Far & 0 & 4170 \\
\hline 5 & 850 & 1.207 & 1280 & 2470 & 0.529 & 55.7 & 0.861 & 0.039 & Far & 0 & 4170 \\
\hline 6 & 1021 & 1.209 & 1480 & 2720 & 0.553 & 61.2 & 0.863 & 0.038 & Far & 0 & 4170 \\
\hline 7 & 1179 & 1.208 & 1660 & 2920 & 0.567 & 65.8 & 0.862 & 0.034 & Far & 0 & 4170 \\
\hline 8 & 1396 & 1.206 & 1920 & 3180 & 0.581 & 71.5 & 0.861 & 0.030 & Far & 0 & 4170 \\
\hline 9 & 1567 & 1.207 & 2120 & 3360 & 0.589 & 75.8 & 0.861 & 0.028 & Far & 0 & 4170 \\
\hline 10 & 1800 & 1.206 & 2400 & 3600 & 0.597 & 81.1 & 0.860 & 0.027 & Far & 0 & 4166 \\
\hline 11 & 1021 & 1.204 & 1480 & 2710 & 0.550 & 61 & 0.860 & 0.037 & Near & -13 & 1520 \\
\hline 12 & 1179 & 2.716 & 3630 & 3270 & 0.650 & 147 & 0.892 & 0.082 & Far & 0 & 4170 \\
\hline 13 & 1800 & 2.720 & 5302 & 4050 & 0.682 & 182 & 0.894 & 0.067 & Far & 0 & 4170 \\
\hline 14 & 1179 & 3.122 & 4150 & 3290 & 0.657 & 169 & 0.890 & 0.100 & Far & 0 & 4170 \\
\hline 15 & 1800 & 3.112 & 6050 & 4070 & 0.689 & 209 & 0.890 & 0.081 & Far & 0 & 4170 \\
\hline 16 & 1179 & 3.542 & 4710 & 3330 & 0.665 & 192 & 0.892 & 0.116 & Far & 0 & 4170 \\
\hline 17 & 1396 & 3.542 & 5464 & 3620 & 0.679 & 209 & 0.892 & 0.103 & Far & 0 & 4170 \\
\hline 18 & 1567 & 3.545 & 6060 & 3840 & 0.688 & 222 & 0.893 & 0.099 & Far & 0 & 4170 \\
\hline 19 & 1800 & 3.546 & 6880 & 4120 & 0.697 & 238 & 0.893 & 0.095 & Far & 0 & 4170 \\
\hline 20 & 1021 & 1.244 & 1520 & 2800 & 0.569 & 62.9 & 0.889 & 0.034 & Far & 0 & 4170 \\
\hline 21 & 1021 & 1.244 & 1520 & 2800 & 0.569 & 62.9 & 0.889 & 0.032 & Near & -13 & 1520 \\
\hline 22 & 1800 & 3.118 & 6060 & 4080 & 0.690 & 209 & 0.892 & 0.081 & Far & 0 & 4170 \\
\hline 23 & 1800 & 3.118 & 6060 & 4080 & 0.690 & 209 & 0.892 & 0.087 & Near & -13 & 1520 \\
\hline 24 & 1800 & 3.540 & 6870 & 4080 & 0.691 & 237 & 0.892 & 0.091 & Far & 0 & 4170 \\
\hline 25 & 1800 & 3.540 & 6870 & 4080 & 0.691 & 237 & 0.892 & 0.094 & Near & -13 & 1520 \\
\hline $26^{\mathrm{a}}$ & 1800 & 3.540 & 6870 & 4080 & 0.691 & 237 & 0.892 & 0.087 & Near & -13 & 1520 \\
\hline $26^{\mathrm{b}}$ & 1800 & 3.540 & 6870 & 4080 & 0.691 & 237 & 0.892 & 0.100 & Near & 0 & 1520 \\
\hline $26^{\mathrm{c}}$ & 1800 & 3.540 & 6870 & 4080 & 0.691 & 237 & 0.892 & 0.092 & Near & 13 & 1520 \\
\hline
\end{tabular}

a, b, ${ }^{c}$ Near-field ExB probe operated in sweep mode.

The oscilloscope trace of the far-field $\mathbf{E} x \mathbf{B}$ relative ion current collected for the above operating point is presented in figure 6. The bias-plate potentials corresponding to the $\mathrm{J}^{+}$and $\mathrm{J}^{++}$peaks are centered at 65.6 and $91.6 \mathrm{~V}$, respectively. To calculate the ion current ratio $\mathrm{J}^{++} / \mathrm{J}^{+}$, the small voltage offset (approximately equal to 0.023 percent of $\mathrm{J}^{+}$) was subtracted from both ion currents, resulting in $\mathrm{J}^{++} / \mathrm{J}^{+}$equal to 0.091 for this case. The fullwidth signal span is approximately $28 \mathrm{~V}$ for the $\mathrm{J}^{+}$ions and approximately $25 \mathrm{~V}$ for the $\mathrm{J}^{++}$ions. In order to maximize the number of ions collected by the far-field probe, relatively large collimating apertures were used. It can be seen from figure 6 that the peaks have a gentle maximum, indicative of partial signal passage at any bias-plate potential. In order to obtain flat top peaks with the given collimator geometry, a substantially larger exit slit width is required. However, a larger slit would have resulted in undesirable overlap of the peaks. The choice of large collimating apertures to assure signal clarity essentially dictated the shape of the signal traces. The possible sources of error in ExB measurements are discussed in the literature. ${ }^{14,15}$ 


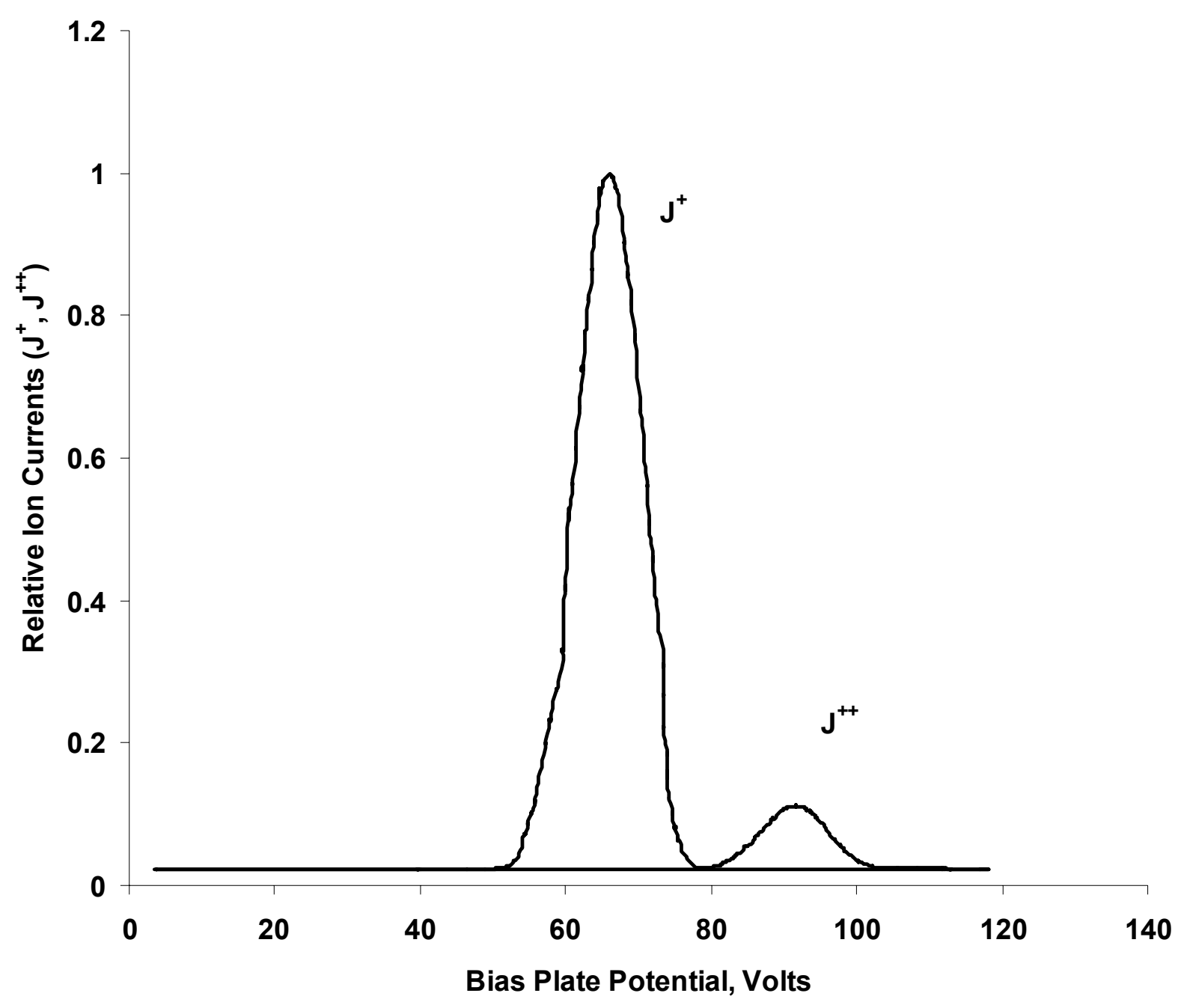

Figure 6.-Far-field ExB probe trace.

Next, for the same operating condition, the oscilloscope trace of relative ion current measured by the near-field $\mathbf{E} x \mathbf{B}$ probe is presented figure 7. Taking the offset into account for this case, $\mathrm{J}^{++} / \mathrm{J}^{+}$equals 0.094 . In this instance, the plateaus corresponding to the $\mathrm{J}^{+}$and $\mathrm{J}^{++}$currents are centered at values of 197.6 and $279.4 \mathrm{~V}$ bias-plate potential, respectively. The full-width signal span is approximately $51 \mathrm{~V}$ for the $\mathrm{J}^{+}$ions and approximately $43 \mathrm{~V}$ for the $\mathrm{J}^{++}$ ions. By visual inspection of the traces obtained from each of the probes, or by normalizing the signal widths with respect to the corresponding separation between the $\mathrm{J}^{+}$and the $\mathrm{J}^{++}$peaks, the near-field probe is seen to provide better signal resolution. 


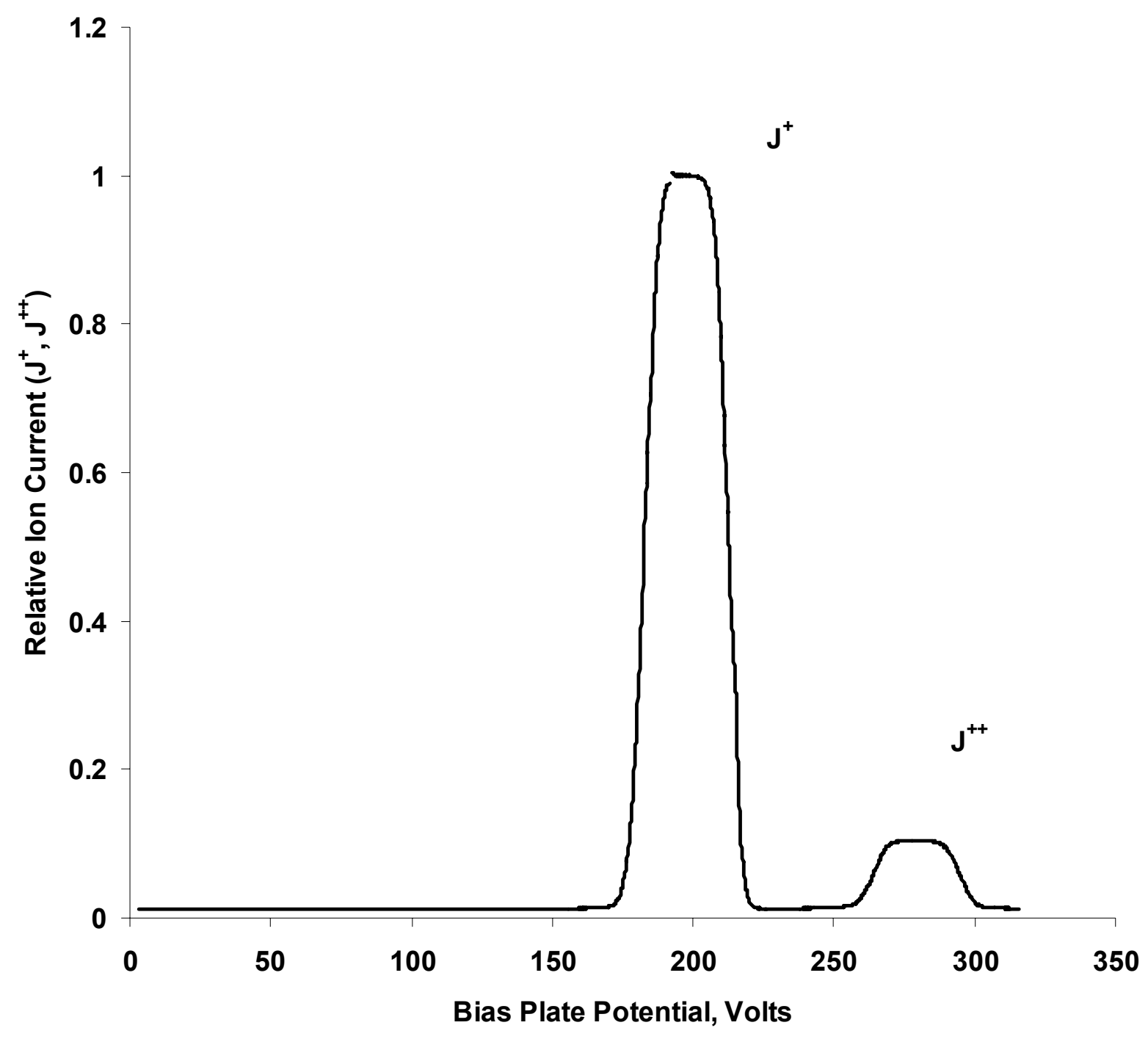

Figure 7.- Near-field ExB probe trace.

Finally, for the same operating condition, oscilloscope traces are presented in figure 8 for the near-field probe operated in the sweep mode. First, to produce a radial $\mathbf{J}^{+}$profile, the probe swept $(16 \mathrm{~mm} / \mathrm{s})$ the plume with an applied bias plate voltage of $198.3 \mathrm{~V}$, which from the above results corresponds closely to the center of $\mathrm{J}^{+}$plateau. Then, to produce a radial $\mathrm{J}^{++}$profile, the probe traversed the plume once again, but with an applied bias plate voltage of $279.7 \mathrm{~V}$, which from the above results corresponds closely to the center of $\mathrm{J}^{++}$plateau. Despite the noise present in the two traces, a considerable amount of right-to-left symmetry is evident. For both the $\mathrm{J}^{+}$and $\mathrm{J}^{++}$traces, the signal falls to a negligible level at the thruster's edges, $\pm 20 \mathrm{~cm}$. The probe did not have an angular articulating capability and thus the $\mathbf{E} x \mathbf{B}$ measured only axially directed ions. Without knowing the angular dependence of ion flux, it is not possible to determine the radial variation in ion currents. 


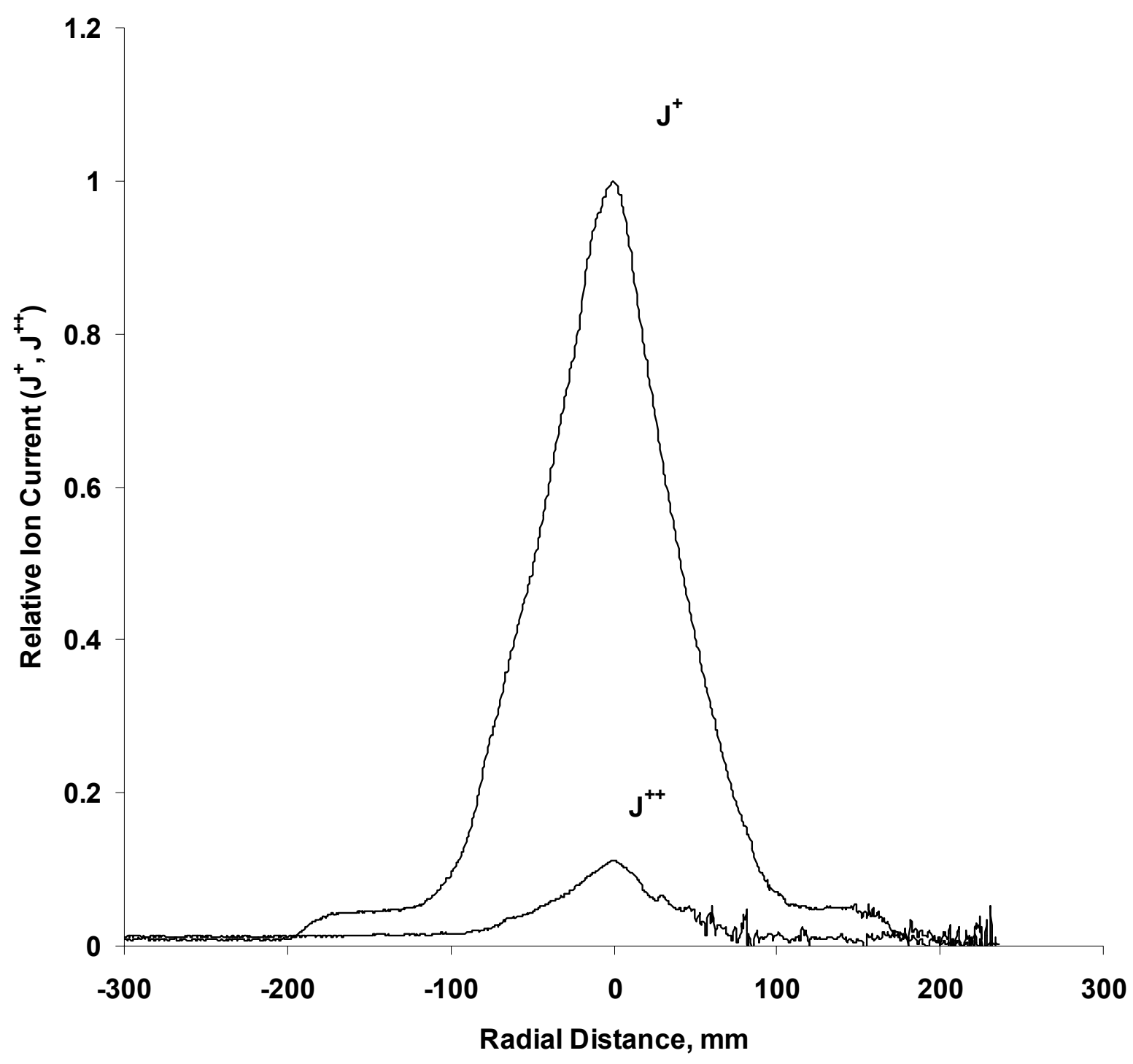

Figure 8. - Near-field ExB probe traces using sweep mode.

To complete the comparison at this operating condition, figure 9 presents the variation in double-to-single ion ratio corresponding to the central $30 \mathrm{~mm}$ portion of the traces presented above in Fig 8. From figure 9, the maximum in $\mathrm{J}^{++} / \mathrm{J}^{+}$occurs on-axis and is equal to approximately 0.1 , with a 12 to 14 percent drop off occurring over the $\pm 15 \mathrm{~cm}$ span shown. For ions exiting the ion optics having paraxial trajectories, the fraction of $\mathrm{Xe}^{++}$ions to $\mathrm{Xe}^{+}$ions decreases with increasing radius. Knowledge of the ion ratio variation does not convey complete information concerning the relative radial dependence of species production within the discharge chamber since the originating direction of a paraxial beam ion can be non-axial. 


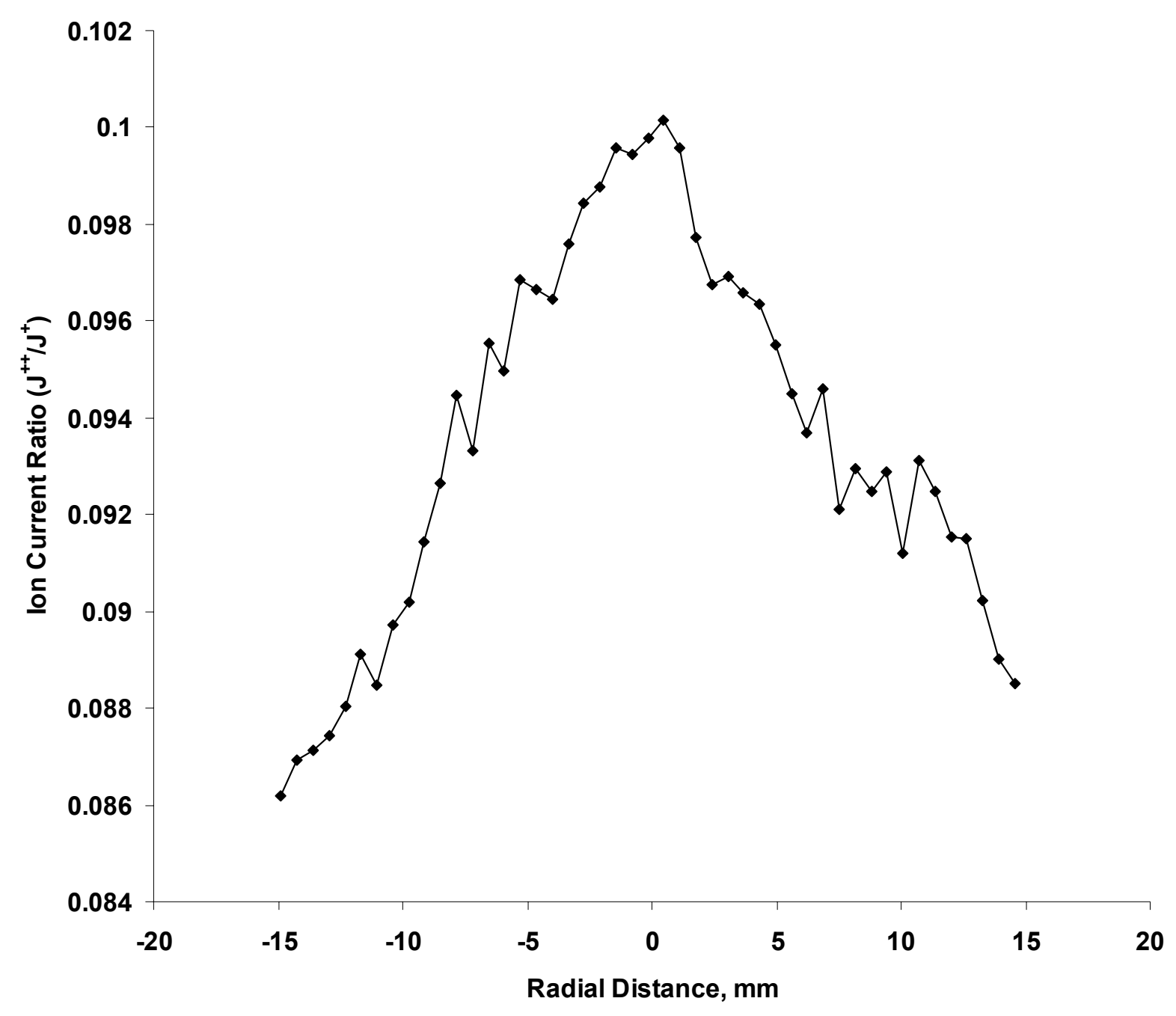

Figure 9. $-\mathrm{J}^{++} / \mathbf{J}^{+}$from near-field ExB probe traces using sweep mode.

Relative ion current data is now presented for a variation of thruster operating conditions with constant propellant utilization efficiency. Figure 10 shows results, obtained using the far-field $\mathbf{E} x \mathbf{B}$ probe, of the dependence of $\mathbf{J}^{++} / \mathbf{J}^{+}$upon beam potential for various values of beam currents, with the total xenon mass flow rate corresponding to a particular curve also a constant. The propellant utilization efficiency is 0.89 for all the curves except for the lowest current curve $\left(1.2 \mathrm{~A}\right.$ ), in which case it is equal to 0.86 . The ion current ratios $\mathrm{J}^{++} / \mathrm{J}^{+}$increase strongly with increasing beam current while decreasing moderately with increasing beam potential. The modest decrease along a curve in $\mathrm{J}^{++} / \mathrm{J}^{+}$with increasing $\mathrm{V}_{\mathrm{b}}$ is associated with a corresponding decrease in discharge current. When the $\mathrm{J}^{++} / \mathrm{J}^{+}$ ratios are shown as a function of input power $P_{i n}$ at various levels of $V_{b}$, a family of essentially linear curves is obtained. Figure 11 shows these curves. The figure shows that, for the same input power, the ratio $\mathrm{J}^{++} / \mathrm{J}^{+}$is lower for higher $V_{b}$, and this distinction increases with increasing $P_{\text {in }}$ since the curves diverge with higher power. 


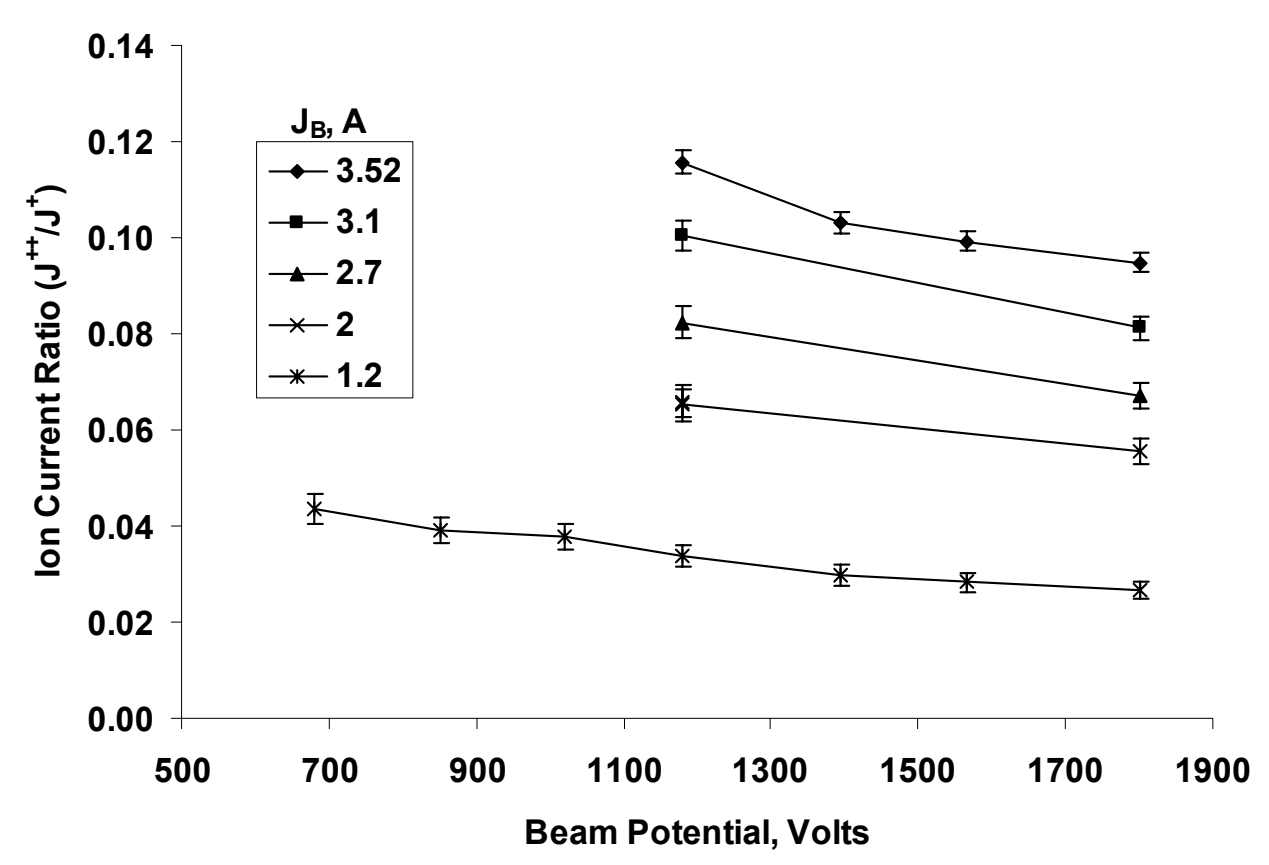

Figure 10.--Ion current ratios $\left(\mathrm{J}^{++} / \mathrm{J}^{+}\right)$versus beam potential.

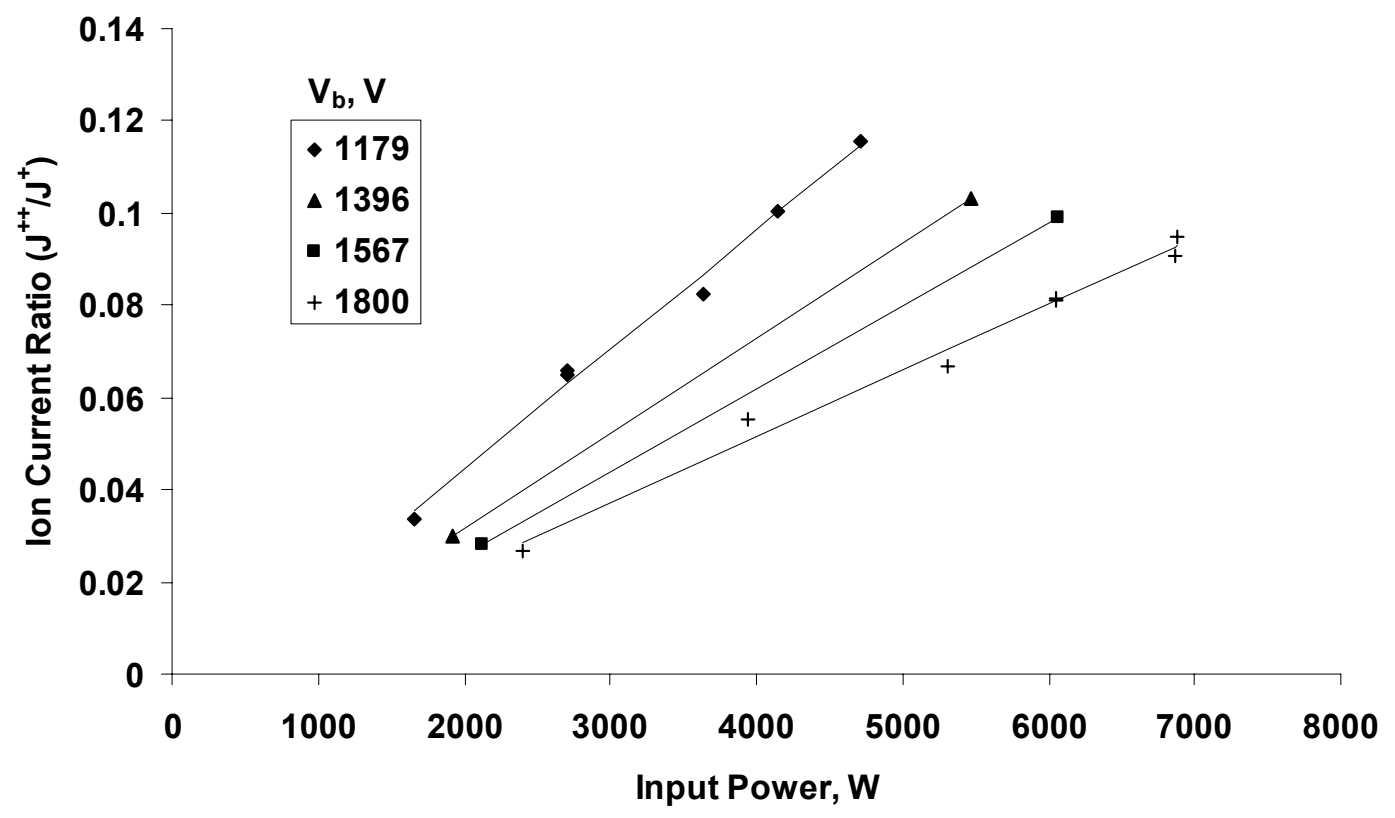

Figure 11.- Ion current ratios $\left(\mathrm{J}^{++} / \mathrm{J}^{+}\right)$versus input power.

2. $J^{++} / J^{+}$with PPU and PMS

With the Aerojet PMS delivering the xenon propellant and the PPU providing thruster power, a second set of $\mathbf{E} x \mathbf{B}$ probe measurements were obtained on the plume. During this portion of the test the thruster was operated over a range of propellant utilization efficiencies. Only near-field $\mathbf{E} x \mathbf{B}$ measurements were obtained for this set of data. A synopsis of the data is presented in table IV with the data arranged chronologically. The PPU data sets were obtained over a two day period and are grouped into two sets accordingly. 
Table IV.-SSIT EPT EM2 Using PPU and PMS.

\begin{tabular}{|c|c|c|c|c|c|c|c|c|c|}
\hline Point & $\begin{array}{c}\mathrm{V}_{\mathrm{bps}} \\
\mathrm{V} \\
\end{array}$ & $\begin{array}{c}\mathrm{J}_{\mathrm{bps}} \\
\mathrm{A} \\
\end{array}$ & $\begin{array}{l}P_{\text {in }} \\
W\end{array}$ & $\begin{array}{c}\text { Specific } \\
\text { Impulse } \\
\mathrm{S} \\
\end{array}$ & Thrust Eff. & $\begin{array}{c}\text { Thrust } \\
\mathrm{mN}\end{array}$ & $\begin{array}{l}\text { Dis. Prop. } \\
\text { Eff. }\end{array}$ & $\mathbf{J}^{++} / \mathbf{J}^{+}$ & $\begin{array}{c}\mathrm{x} \\
\mathrm{mm} \\
\end{array}$ \\
\hline 27 & 1800 & 3.538 & 6860 & 4120 & 0.699 & 238 & 0.894 & 0.102 & -13 \\
\hline 28 & 1800 & 3.538 & 6860 & 4120 & 0.699 & 238 & 0.894 & 0.113 & 0 \\
\hline 29 & 1800 & 3.538 & 6860 & 4120 & 0.699 & 238 & 0.894 & 0.107 & 13 \\
\hline $30^{\mathrm{a}}$ & 1800 & 3.538 & 6860 & 4120 & 0.699 & 238 & 0.894 & 0.096 & -13 \\
\hline $30^{\mathrm{b}}$ & 1800 & 3.538 & 6860 & 4120 & 0.699 & 238 & 0.894 & 0.118 & 0 \\
\hline $30^{\mathrm{c}}$ & 1800 & 3.538 & 6860 & 4120 & 0.699 & 238 & 0.894 & 0.107 & 13 \\
\hline 31 & 1179 & 2.012 & 2720 & 3190 & 0.627 & 109 & 0.892 & 0.089 & -13 \\
\hline 32 & 1179 & 2.012 & 2720 & 3190 & 0.627 & 109 & 0.892 & 0.090 & 0 \\
\hline 33 & 1179 & 2.012 & 2720 & 3190 & 0.627 & 109 & 0.892 & 0.085 & 13 \\
\hline $34^{\mathrm{a}}$ & 1179 & 2.009 & 2720 & 3180 & 0.627 & 109 & 0.896 & 0.066 & -13 \\
\hline $34^{\mathrm{b}}$ & 1179 & 2.009 & 2720 & 3180 & 0.627 & 109 & 0.896 & 0.075 & 0 \\
\hline $34^{\mathrm{c}}$ & 1179 & 2.009 & 2720 & 3180 & 0.627 & 109 & 0.896 & 0.065 & 13 \\
\hline 35 & 1800 & 3.532 & 6860 & 4110 & 0.697 & 237 & 0.892 & 0.109 & 0 \\
\hline 36 & 1800 & 3.525 & 6880 & 4310 & 0.722 & 235 & 0.946 & 0.176 & 0 \\
\hline 37 & 1800 & 3.530 & 6870 & 4210 & 0.711 & 236 & 0.919 & 0.134 & 0 \\
\hline 38 & 1800 & 3.533 & 6840 & 3930 & 0.671 & 238 & 0.845 & 0.081 & 0 \\
\hline 39 & 1179 & 2.008 & 2710 & 3180 & 0.628 & 109 & 0.891 & 0.081 & 0 \\
\hline 40 & 1179 & 2.006 & 2760 & 3370 & 0.647 & 108 & 0.960 & 0.158 & 0 \\
\hline 41 & 1179 & 2.005 & 2780 & 3310 & 0.633 & 108 & 0.928 & 0.115 & 0 \\
\hline 42 & 1179 & 2.002 & 2680 & 3020 & 0.603 & 109 & 0.835 & 0.056 & 0 \\
\hline
\end{tabular}

${ }_{\text {a, b, }}$ Near-field ExB probe operated in sweep mode. y-position of probe $=1520 \mathrm{~mm}$.

Figure 12 shows results, obtained using the far-field ExB probe, of the dependence of $\mathrm{J}^{++} / \mathrm{J}^{+}$upon propellant utilization efficiency for beam potentials of 1179 and $1800 \mathrm{~V}$. The figure legend denotes the beam currents corresponding to the two cases in terms of the nominal throttle values, respectively. The actual beam currents (as listed in table IV) for each point deviate from nominal throttle operation slightly. As characteristic with this function, the ion current ratio $\mathrm{J}^{++} / \mathrm{J}^{+}$increases monotonically with increasing utilization efficiency. The degree of sharpness in the knee of the curve determines the tradeoff between higher efficiencies and lower $\mathrm{J}^{++} / \mathrm{J}^{+}$. 


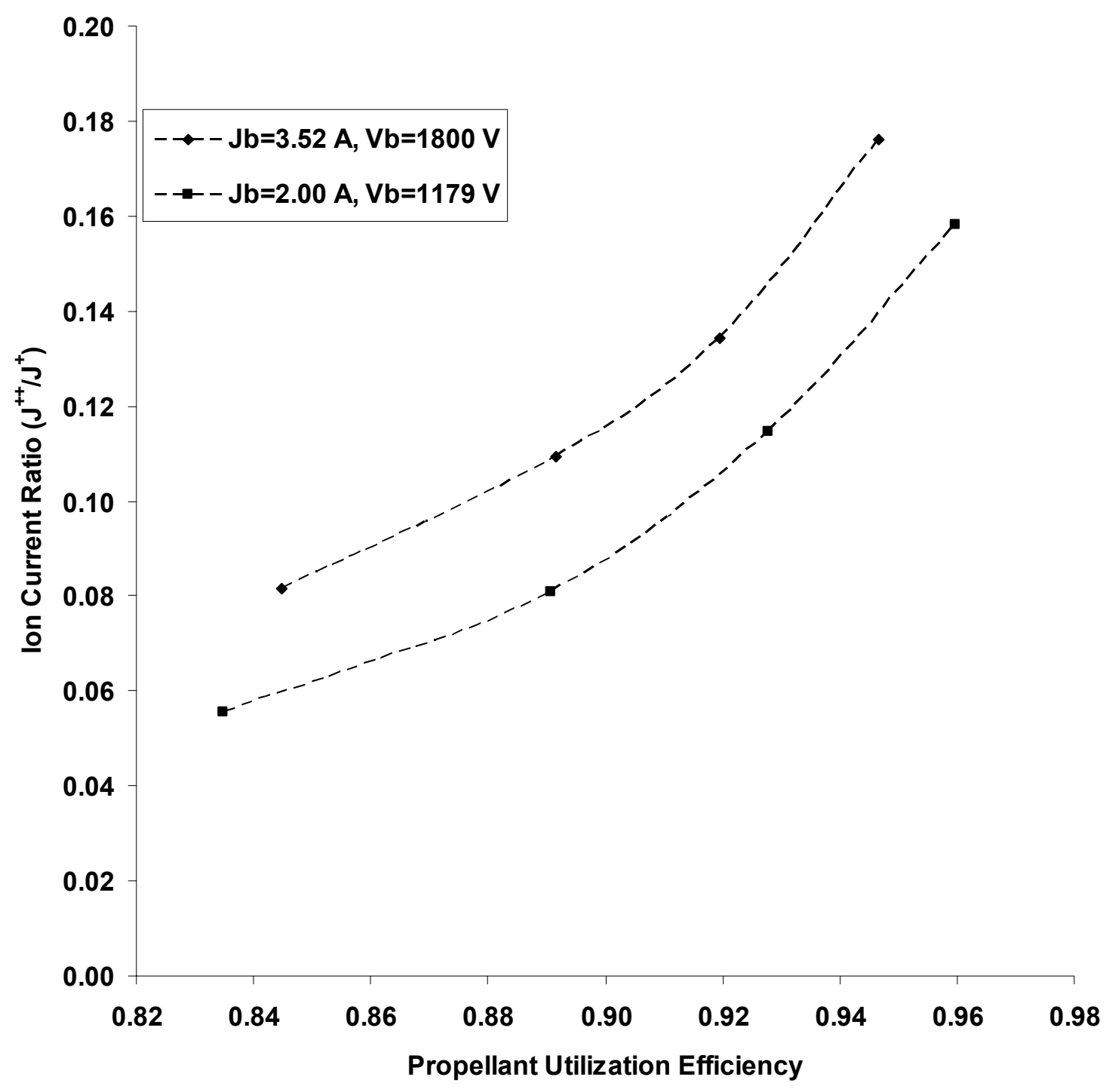

Figure 12.--Ion current ratios $\left(\mathrm{J}^{++} / \mathrm{J}^{+}\right)$versus propellant utilization efficiency.

For comparison purposes, the data presented in figure 12 is shown again in figure 13 along with NSTAR ${ }^{16}$ data obtained from a number of $30 \mathrm{~cm}$ diameter xenon thruster tests. The NSTAR data presented here is for thruster operation at the NSTAR TH15 throttle level and includes data from the following tests: Pathfinder (PFT); Flight Thruster number 1 (FT1); and Flight Thruster number 2 (FT2), which resulted from refurbishing PFT. The number following the dash in the legend list of figure 13 denotes the functional data number of the corresponding NSTAR test. The TH15 level is the NSTAR full power level; nominal full power operation designates a beam voltage of $1100 \mathrm{~V}$, beam current of $1.76 \mathrm{~A}$, and thruster power of $2.29 \mathrm{~kW}$. The NSTAR discharge propellant utilization efficiency achieved at full power was essentially 90 percent. In contrast to the probes used in the SSIT, which used circular collimating apertures and sampled ions within circular disks (table I), the ExB probe used for the NSTAR data had a collimating system that sampled ions emitted from a rectangular strip $1.8 \mathrm{~cm}$ wide strip spanning the diameter of the thruster. Furthermore, the NSTAR probe-to-thruster distance was $6 \mathrm{~m}$, exceeding the SSIT far-field probe distance by more than $1.5 \mathrm{~m}$. In comparison to the NSTAR data, the SSIT double-to-single ion ratio at 90 percent efficiency is lower for the $\mathrm{V}_{\mathrm{b}}=1179 \mathrm{~V}$ case (which is nearer to the NSTAR throttle TH15 level than the $\operatorname{SSIT~}_{\mathrm{b}}=1800 \mathrm{~V}$ data.) 


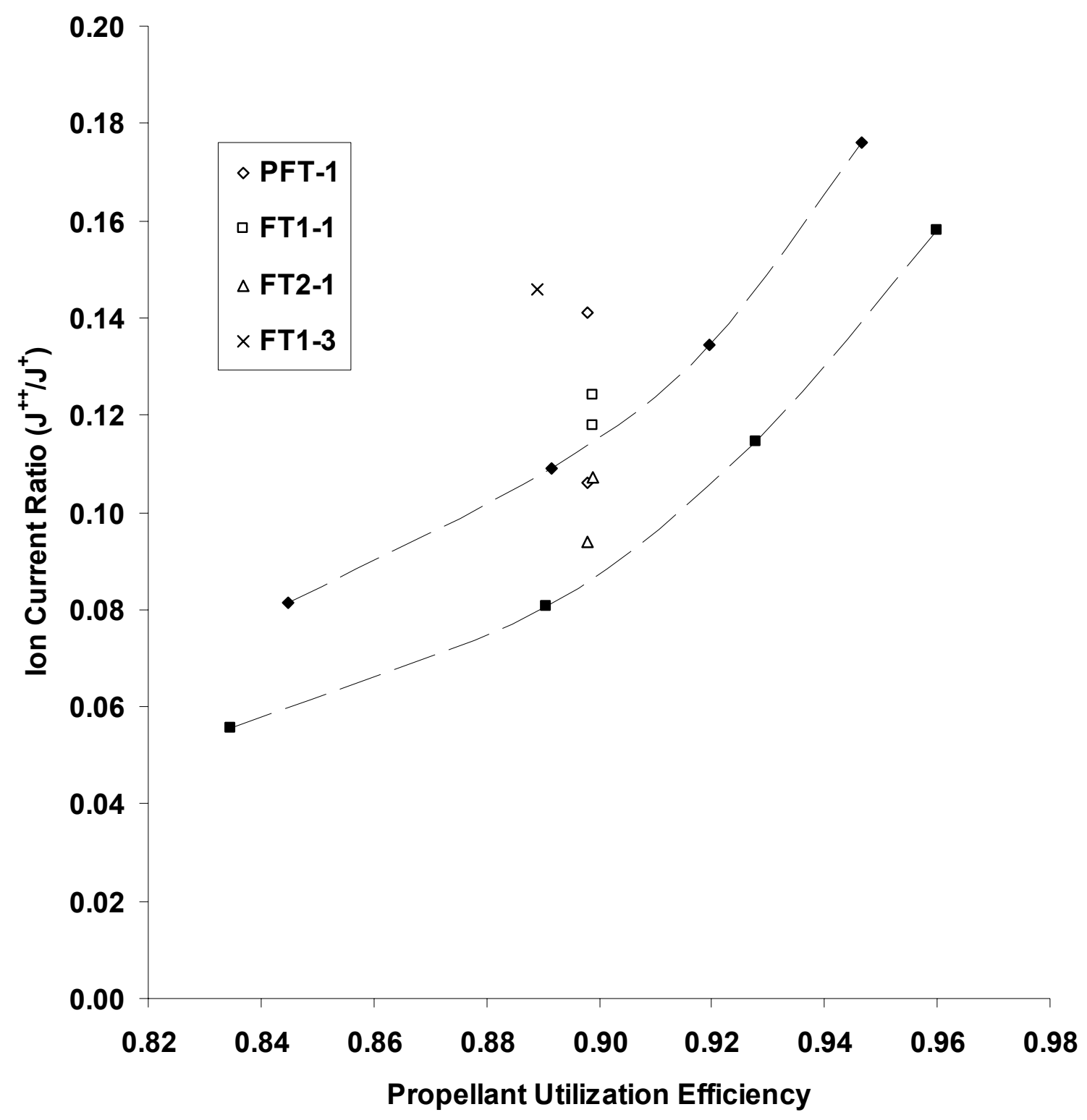

Figure 13.-Comparison of SSIT and NSTAR ion current ratios $\left(\mathrm{J}^{++} / \mathrm{J}^{+}\right)$.

\section{Conclusion}

SSIT beam diagnostic results of the EM2 NEXT 40-cm ion engine were presented. Plume measurements were obtained over a broad range of the NEXT throttle table while operating the thruster with an advanced xenon PMS and providing power sequentially, using initially a power console before progressing to the PPU achieving full system integration. Radial beam profiles and double-to-single ion ratios were obtained and compared to Phase I SSIT performance data and NSTAR data, respectively. The primary goal of documenting the SSIT plume was achieved. The diagnostic results of the EM2 plume presented in this paper should provide a valuable aid in characterizing engine operation. It is hoped that the results will clarify component lifetime issues as well as provide insight and guidance in the preparation of extended throttle tables for the purpose of enhancing both the performance and flexibility of ion engines regarding future missions. 


\section{References}

${ }^{1}$ IPolk, J.E., et al., In-Flight Performance of the NSTAR Ion propulsion System on the Deep Space One Mission, IEEE Aerospace Conference Paper No. 8.0304 (March 2000).

${ }^{2}$ Benson, S.W. and Patterson, M.J., Development Status of NEXT: NASA's Evolutionary Xenon Thruster, IEPC Paper No. 030288 (March 2003).

${ }^{3}$ Patterson, M.J., ET AL., NEXT-Generation 5/10 kW Ion Propulsion Development Status, IEPC Paper No. 01-089 (October 2001).

${ }^{4}$ Soulas, G.C., Design and Performance of $40 \mathrm{~cm}$ Ion Optics, IEPC Paper No. 01-090 (October 2001).

${ }^{5}$ Soulas, G.C., Domonkos, M.T., and Patterson, M.J., Performance Evaluation of the Next Ion Engine, AIAA Paper No. 2003-5278 (July 2003).

${ }^{6}$ Patterson, M.J., et al., NEXT-NASA's Evolutionary Xenon Thruster Development Status, AIAA Paper No. $2003-4862$ (July 2003).

${ }^{7}$ Grisnik, S.P., et al., A Large High Vacuum, High Pumping Speed Space Simulation Chamber for Electric Propulsion, Prepared for the $23^{\text {rd }}$ International Electric Propulsion Conference cosponsored by the AIAA, AIDAA, DGLR, JSASS Seattle, Washington (September 1993).

${ }^{8}$ Piñero, L.R. , et al., Design of a Modular 5-kW Power Processing Unit for the NEXT-Generation 40-cm Ion Engine, IEPC Paper No. 01-329 (October 2001).

${ }^{9}$ Phelps, T.K. et al., Development of the NEXT Power Processing Unit, AIAA Paper No. 2003-4867 (July 2003).

${ }^{10}$ Fisher, J., et al., The Development and Qualification of a $4.5 \mathrm{~kW}$ Hall Thruster Propulsion System, JANNAF Proceedings (November 2002).

${ }^{11}$ Kamhawi, H., et al., "NEXT Ion Engine 2000 Hour Wear Test Plume and Erosion Results," AIAA Paper 2004-3792, (July 2004)

${ }^{12}$ Soulas, G.C., Performance Evaluation of Titanium Ion Optics for the NASA $30 \mathrm{~cm}$ Ion Thruster, IEPC Paper No. 01-092 (October 2001).

${ }^{13}$ Soulas, G.C., Performance of Titanium Optics on a NASA 30 cm Ion Thruster, AIAA Paper No. 2000-3814 (July 2000).

${ }^{14}$ Hofer, R.R., et al., Ion Species Fraction in the Far-field Plume of a High-Specific Impulse hall Thruster, AIAA Paper No. 2003-5001 (July 2003).

${ }^{15}$ Kim, S.-W., Experimental Investigations of Plasma Parameters and Species-Dependent Ion Energy Distribution in the Plasma Exhaust Plume of a Hall Thruster, PhD Dissertation, Dept. of Aerospace Engineering, Univ. of Michigan, Ann Arbor, MI, (August 1998).

${ }^{16}$ Rawlin, V.K., et al., NSTAR Flight Thruster Qualification Testing, AIAA Paper No. 98-3936 (July 1998). 


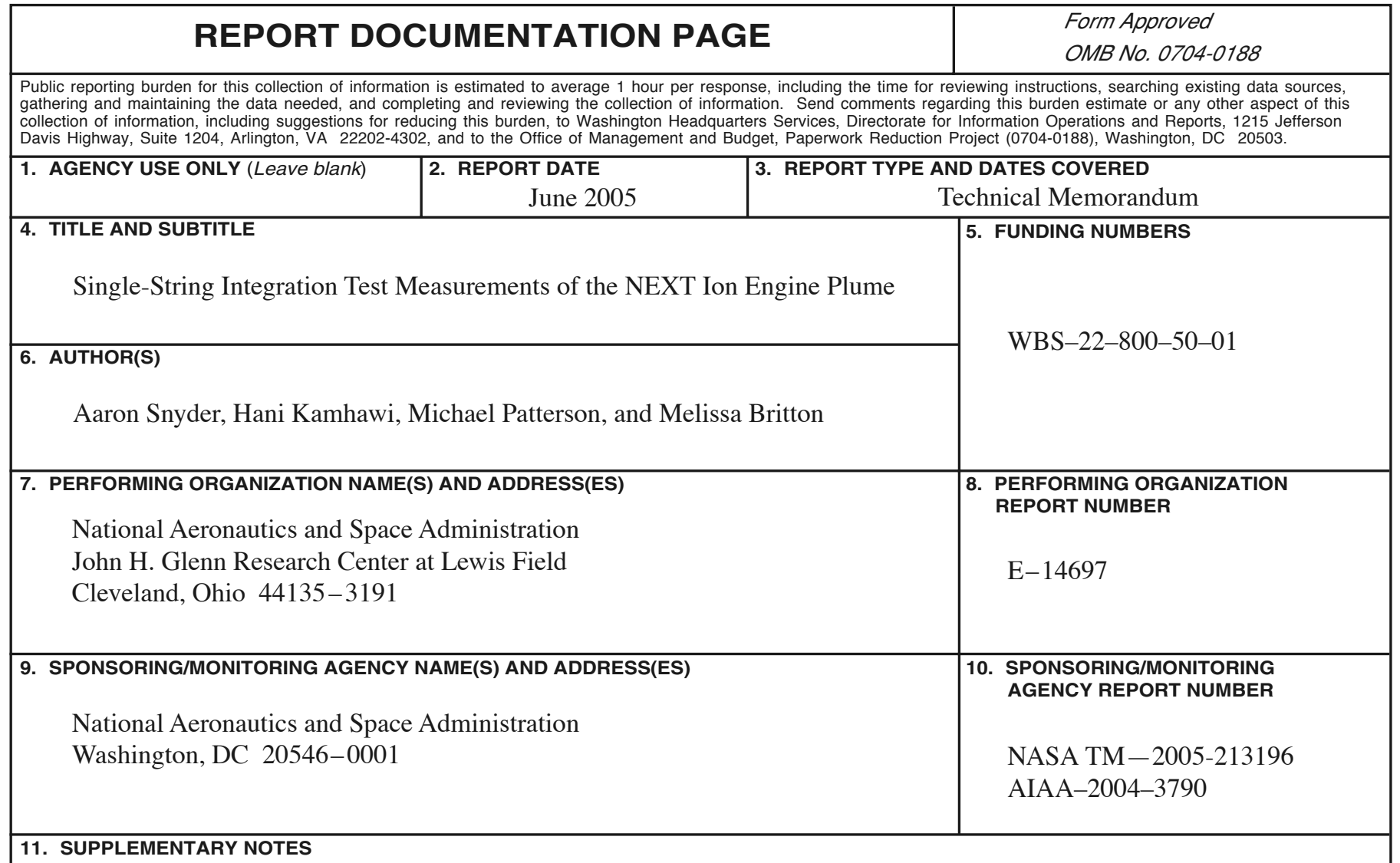

Prepared for the 40th Joint Propulsion Conference and Exhibit cosponsored by the AIAA, ASME, SAE, and ASEE, Fort Lauderdale, Florida, July 11-14, 2004. Aaron Snyder, Hani Kamhawi, and Michael Patterson, NASA Glenn Research Center; and Melissa Britton, QSS Group, Inc., 21000 Brookpark Road, Cleveland, Ohio 44135. Responsible person, Aaron Snyder, organization code RPY, 216-433-5918.

\begin{tabular}{|l|l|}
\hline 12a. DISTRIBUTION/AVAILABILITY STATEMENT & 12b. DISTRIBUTION CODE
\end{tabular}

Unclassified - Unlimited

Subject Categories: 20 and 75

Available electronically at http://gltrs.grc.nasa.gov

This publication is available from the NASA Center for AeroSpace Information, 301-621-0390.

13. ABSTRACT (Maximum 200 words)

Measurements were made of a $40 \mathrm{~cm}$ ion-thruster plume as part of the single-string-integration-test (SSIT) activity of Phase I of the NASA's Evolutionary Xenon Thruster (NEXT) project. The NEXT ion engine incorporates design improvements that extend NSTAR power levels and efficiencies. During SSIT, an engineering model (EM2) $40 \mathrm{~cm}$ engine was operated using an advanced xenon propellant system in combination with either a GRC power console or advanced power processing unit. Integral goals of the single-string phase were to characterize engine performance over the full input power range and to detail thruster operation within the specification of the NEXT throttle table. Plume diagnostics measurements of relative $\mathrm{Xe}^{+}$and $\mathrm{Xe}^{++}$currents were made using near-field and far-field ExB probes. Planar geometry faraday probes were used to obtain beam current density profiles. This paper reports on the characterization of the EM2 plume over a range of SSIT operating conditions, first with the advanced propellant management system teamed with the GRC power console and then with the power-processing unit.

14. SUBJECT TERMS

Plume diagnostics; Ion engine

\begin{tabular}{|c|c|c|}
\hline $\begin{array}{c}\text { 17. SECURITY CLASSIFICATION } \\
\text { OF REPORT } \\
\text { Unclassified }\end{array}$ & $\begin{array}{c}\text { 18. SECURITY CLASSIFICATION } \\
\text { OF THIS PAGE } \\
\text { Unclassified }\end{array}$ & $\begin{array}{c}\text { 19. SECURITY CLASSIFICATION } \\
\text { OF ABSTRACT } \\
\text { Unclassified }\end{array}$ \\
\hline
\end{tabular}

NSN 7540-01-280-5500

Standard Form 298 (Rev. 2-89)

Prescribed by ANSI Std. Z39-18 298-102 

